Please do not remove this page

RMIT

UNIVERSITY

\title{
A greenhouse gas assessment of a stadium in Australia
}

Hedayati, Mehdi; Iyer-Raniga, Usha; Crossin, Enda

https://researchrepository.rmit.edu.au/esploro/outputs/9921859480501341/filesAndLinks?institution=61RMIT_INST\&index=null

Hedayati, M., Iyer-Raniga, U., \& Crossin, E. (2014). A greenhouse gas assessment of a stadium in Australia. Building Research and Information, 42(5), 602-615. https://doi.org/10.1080/09613218.2014.896141

Document Version: Submitted Version

Published Version: https://doi.org/10.1080/09613218.2014.896141

Repository homepage: https://researchrepository.rmit.edu.au

(C) 2014 Taylor and Francis

Downloaded On 2023/04/26 20:55:40 +1000

Please do not remove this page 
Thank you for downloading this document from the RMIT Research Repository.

The RMIT Research Repository is an open access database showcasing the research outputs of RMIT University researchers.

RMIT Research Repository: http://researchbank.rmit.edu.au/

\section{Citation:}

Hedayati, M, lyer-Raniga, $U$ and Crossin, E 2014, 'A greenhouse gas assessment of a stadium in Australia', Building Research and Information, vol. 42, no. 5, pp. 602-615.

See this record in the RMIT Research Repository at:

https://researchbank.rmit.edu.au/view/rmit:24478

Version: Submitted Version

Copyright Statement: (c) 2014 Taylor and Francis

Link to Published Version:

http://dx.doi.org/10.1080/09613218.2014.896141 


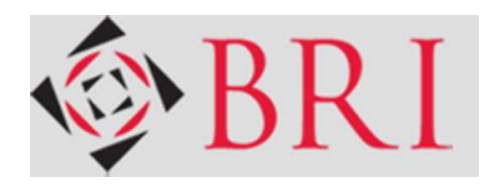

\section{A greenhouse gas assessment of a Stadium in Australia}

\begin{tabular}{|c|c|}
\hline Journal: & Building Research \& Information \\
\hline Manuscript ID: & 13BR0017-RE.R2 \\
\hline Manuscript Type: & Research Paper \\
\hline Keywords: & $\begin{array}{l}\text { life cycle assessment (LCA), greenhouse gases (GHG), energy, } \\
\text { sustainability }\end{array}$ \\
\hline Other keywords: & stadium, sporting events \\
\hline Abstract: & $\begin{array}{l}\text { This paper presents the findings of a greenhouse gas life cycle assessment } \\
\text { of a stadium used for sporting events in a sub-tropical region in Australia. } \\
\text { Inventories for the construction and operation of a stadium are presented } \\
\text { and the greenhouse gas emissions from construction, operations and end- } \\
\text { of-life waste management are assessed against the attendance of one } \\
\text { person at one event. The inclusion of additional economic activities, patron } \\
\text { travel, LCA methodology, attendance and stadium life time assumptions, } \\
\text { are likely to affect the overall magnitude of the greenhouse gas emissions } \\
\text { of one person's' attendance. The assessment shows that the stadium } \\
\text { operation accounted for } 72.5 \% \text { of greenhouse gas emissions, with the } \\
\text { operation of base load heating, ventilation and cooling, lighting and } \\
\text { refrigeration systems dominating. Addressing the continual operation of } \\
\text { these systems represents the best opportunity to reduce greenhouse } \\
\text { emissions. Construction impacts account for } 24.7 \% \text { of impacts, while } \\
\text { replacement materials, end of life management of materials are relatively } \\
\text { insignificant, contributing to less than } 3 \% \text { of life cycle greenhouse } \\
\text { emissions. }\end{array}$ \\
\hline
\end{tabular}

SCHOLARONE $^{\text {m }}$

Manuscripts 
A greenhouse gas assessment of a Stadium in Australia 


\section{A greenhouse gas assessment of a Stadium in Australia}

This paper presents the findings of a greenhouse gas life cycle assessment of a stadium used for sporting events in a sub-tropical region in Australia. Inventories for the construction and operation of a stadium are presented and the greenhouse gas emissions from construction, operations and endof-life waste management are assessed against the attendance of one person at one event. The inclusion of additional economic activities, patron travel, LCA methodology, attendance and stadium life time assumptions, are likely to affect the overall magnitude of the greenhouse gas emissions of one person's' attendance. The assessment shows that the stadium operation accounted for $72.5 \%$ of greenhouse gas emissions, with the operation of base load heating, ventilation and cooling, lighting and refrigeration systems dominating. Addressing the continual operation of these systems represents the best opportunity to reduce greenhouse emissions. Construction impacts account for $24.7 \%$ of impacts, while replacement materials, end of life management of materials are relatively insignificant, contributing to less than $3 \%$ of life cycle greenhouse emissions.

Keywords: life cycle assessment; greenhouse emissions; stadium; sporting events

Subject classification codes: include these here if the journal requires them 


\section{Introduction}

Life cycle assessment (LCA) research has been applied to commercial and residential buildings to better understand environmental impacts and potential environmental mitigation strategies. A number of LCA methods have been utilised for the built environment, including process-based LCA, which accounts for the environmental impacts associated with material and energy flows, and economic input-output (EIO) LCA (Ochoa, Hendrickson, \& Matthews, 2002), which accounts for environmental impacts stemming from economic flows across and within different industry sectors within an economy. Each LCA method has its advantages and disadvantages, some of which are discussed here. Processbased LCA allows for the identification of material and/or energy processes, which drive environmental impacts. A disadvantage of process-based LCA is that it can be time consuming, and as such is limited by the choice of the processes to be included in the assessment (the system boundary). It has been argued that the choice of system boundaries in process-based LCA could exclude between 50\% (Lenzen, 2000) and 87\% (Crawford, 2008) of embodied energy impacts. EOILCA overcomes this limitation by accounting for additional environmental flows associated with a product/service, such as the procurement of professional services (e.g. engineering services). Disadvantages of EIO-LCA include data resolution, which can limit the ability to identify process optimisation and redesign opportunities (Finnveden et al., 2009) and difficulties associated with economic flows beyond the economy being examined (e.g. imports). Hybrid LCA, which combines process-based and EIO LCA has been used to allow for a more 
complete assessment of all environmental flows associated with buildings (Aye, Ngo, Crawford, Gammampila, \& Mendis, 2012; Treloar, Love, Faniran, \& IyerRaniga, 2000).

Irrespective of LCA methodology, the literature on the environmental impacts of sporting stadiums is extremely limited. Collins et al. (2007) reported the ecological footprint (global hectares) and greenhouse gas emissions, using EIO-LCA, of the 2003/04 FA Cup Final at the Millennium Stadium in Cardiff, Wales. The Collins et al. (2007) study accounted for patron transport to the stadium, the provision of food, waste and drink and stadium infrastructure, but excluded stadium operations (e.g. stadium lighting and heating, ventilation and air conditioning systems). This exclusion appears to be a critical oversight as previous process-based LCA studies indicate that the operational impacts of stadiums can contribute to between $31 \%$ and $77 \%$ (Econ Pöyry AB, 2009; Grant, 2001) of total greenhouse gas impacts, depending on the stadium being considered. The greenhouse gas footprint of the 2012 London Olympics were assessed using a hybrid LCA approach (LOC, 2010), but did not include disaggregated results for the stadiums (e.g. Olympic Stadium, Wembley Stadium). The greenhouse gas footprint of the upcoming 2014 FIFA World Cup were assessed using process-based methods (FIFA, 2013).

In addition to these few studies on stadiums, process-based life cycle assessment has been widely applied to assess the potential environmental impacts in other forms of the built environment, namely commercial and residential buildings (Scheuer, Keoleian, \& Reppe, 2003) (Norman, MacLean, \& Kennedy, 2006) (Norman et al., 2006) (Suzuki \& Oka, 1998) (Blengini, 2009) (Li, 2006) 
(Junnila \& Horvath, 2003) (Junnila, Horvath, \& Guggemos, 2006) (Blanchard \& Reppe, 1998) (Carre, 2010) (Kofoworola \& Gheewala, 2008). The difference in the outcomes of these studies is driven by several factors, including regional scope (e.g. due to climatic variations), building lifetime, building construct and life cycle assessment methodology. Regardless of these variations, the same conclusion can be drawn regarding greenhouse impacts. In all cases, the operation and maintenance phase contributes to the majority $(>50 \%)$ of the building greenhouse impacts. This common conclusion is supported by Satrtori and Hestines (2007), who reviewed 60 energy assessment case studies, including those undertaken using LCA. They demonstrated a linear relationship between operational impacts and life cycle impacts and concluded that the most important aspect of residential and commercial building design is to reduce energy use during the operations phase.

This paper presents a case study of a process-based greenhouse gas life cycle assessment of an Australian Football League (AFL) stadium in a subtropical region in Australia. The stadium is a multipurpose facility that currently seats a maximum of 25,000 spectators and is capable of being extended to 40,000 seats in the future. The stadium features an Australian Football League (AFL) oval, which is also capable of holding cricket matches, music concerts, cultural festivals, international athletics events and association football (soccer) matches. The electricity for the stadium is supplied from the Queensland grid and is supplemented by a photovoltaic solar panel system, with the panels installed on the stadium's roof. Water for drinking and catering are supplied by the local municipal reticulated water network. Harvested rain supplies water for non- 
drinking applications, including flushing of toilets and urinals, washing of the stadium, and irrigation of the playing field. The stadium recycles approximately $75 \%$ of glass, paper and cardboard, green waste and comingled plastics generated during sporting events.

This paper adds to the limited body of literature on the environmental impacts of stadiums by firstly providing a disaggregated inventory of the structural materials used in the construction of a stadium. The paper then elucidates on the contribution of the three main life cycle phases by assessing the greenhouse gas emissions related to the main construction materials, as well as those associated with the stadium operation and the end-of life treatment of the construction materials and attendee waste. Finally, this paper identifies specific environmental improvement opportunities by focussing on material and energy process hot-spots.

\section{Method}

The life cycle assessment was undertaken in accordance with the four step procedure for process-LCA outlined in ISO 14040:2006 (ISO, 2006). These four steps include establishing the unit of assessment and system boundary, inventory development, impact assessment and interpretation (results).

\section{Unit of assessment and system boundary}

In LCA, the functional unit is the unit of assessment; all environmental impact results are reported against this unit. The functional unit is intended to reflect the primary function, or service, of a system. Difficulties in defining the primary function of a system can lead to a large variation in reported functional units, 
which can make comparisons between studies problematic. For example, residential and commercial buildings can provide a number of services, including providing shelter, facilitating commercial activities, storage and entertainment. For stadiums, the primary functions are distinctly different to commercial and residential buildings; stadiums can facilitate sports entertainment (e.g. football, baseball or rugby matches), music events or corporate/social events. The primary function of sports stadiums may be defined as the provision of spectator viewing for live sporting events. The hosting of other events (e.g. corporate/social events) is considered to be the stadiums' secondary function.

The functional unit was defined as the provision of entertainment services for attendance of one person at one AFL event in a stadium with a capacity of between 20,000 and 30,000 people.

The system boundary is presented in Figure 1 and includes the main construction and service (e.g. electrical, plumbing) materials, as well as electricity, natural gas, water and waste services associated with stadium operation. The choice of construction materials within the system boundary was based on previous process-based LCAs on stadiums (Econ Pöyry AB, 2009; Grant, 2001; LOC, 2010).

Travel of attendees can be a significant contributor to greenhouse gas impacts at events. For example, Econ Pöyry suggest that travel can account for approximately $85 \%$ of total greenhouse impacts (INSERT REF). This study focuses on identifying environmental improvement opportunities related to materials used in construction, as well as specific operations of the stadium. As such, patron travel, as well as upstream environmental flows associated with 
economic activity (both lower and higher order) typically assessed using EIOLCA have been excluded. The process-based life cycle inventory used accounts for environmental flows associated with major higher-order processes, such as energy and materials throughout the supply chain. However, other higher-order environmental flows associated with economic activity may have been excluded.

As the stadium serves multiple functions, a process on how to partition the stadiums' impacts across these functions is required. There is yet no agreed approach on partitioning in LCA. However, ISO 14044:2006 outlines a stepwise procedure to deal with this partitioning. The first step of the ISO 14044:2006 procedure is to increase the level of detail; that is to collate data relating directly to the different functions. Disaggregated data relating to the operation of the stadium serving different functions (e.g. sporting events, corporate events) was not available. The next step in the ISO 14044:2006 procedure is to account for the effects of the secondary functions (co-products) on other systems; a process often termed system expansion. The system expansion approach suggested by Weidema (Weidema, 2001) was adopted and accounts for potential displacement effects of the hosting of corporate events. Using Weidema's approach, two alternate scenarios are possible. In the first scenario, displacement occurs. That is, the hosting of corporate events at the stadium displaces the hosting of a similar event elsewhere. In this scenario, the sporting event function receives credits associated with the avoidance of hosting of corporate events at another facility (e.g. at a hotel). In the second scenario, displacement does not occur. That is, the hosting of corporate events at the stadium does not displace the hosting of a similar event elsewhere. In the second scenario, the sporting events receive no avoidance 
credits and the corporate events are considered free of environmental burden. The applicability of the two scenarios depends whether or not displacement occurs. Whether or not the displacement of corporate events occurs depends on a number of factors, including the availability of facilities to hold corporate events, the ability of other facilities to fulfil user requirements and decision making (Weidema, 2003). An assessment of substitution effects is beyond the scope of this study. However, the two main industries (as classified by the Australian and New Zealand Industry Code system) most likely to be engaged in hosting corporate events are the hotels and resorts industry, and the pubs, bars and nightclub industry. Both of these industries are forecasting revenue growth, indicating increased demand from consumers for products and services provided by these industries (IBISWorld Pty Ltd., 2013a, 2013b). Increased demand means that the hosting of corporate events at facilities other than the stadium may occur regardless of whether or not the stadium hosts corporate events. In this respect, it is considered unlikely that the corporate events held at the stadium will displace corporate events held elsewhere. Following the second scenario outlined above, this means that the sporting function does not receive avoidance credits.

As per ISO 14044:2006, alternative partition methodologies are applicable if system expansion is not possible. The implications of these alternative partitioning methods are discussed later in this paper.

\section{Inventory}

The second stage in process-based LCA is to develop an inventory of emission flows associated with the materials and energy systems used to deliver the functional unit. 
The stadium is typically used for two pre-season trial games and eleven league game days per calendar year; 13 games in total. The projected economic life of the stadium is 30 years, resulting in a total of 390 game-days. This number of game-days is consistent with other regional stadiums in South Africa (Econ Pöyry AB, 2009). The annual crowd attendance for game days in 2011 was 145,333 for eight matches (Austadiums Website, 2013), an average of 18,166 attendees per match. The average attendance in 2012 was lower, with a total of 160,631 people attending over 13 matches (Austadiums Website, 2013), an average of 12,356 attendees per event, with patronage varying between 5,150 people to 16,550 people. For the purposes of this study, the 2012 attendance figures are used as a basis. In 2012, there were three day games (starting between 2:20 PM and 3:40 PM) and ten night games (starting between 4:40 PM and 7:40 PM). AFL matches typically last for approximately two and a half hours. As such, the games starting at 4:40 PM commence near dusk and are played into the night, with the stadium operating lighting throughout. In addition to the sporting events, the stadium hosted 5,560 attendees at corporate events in 2012. Finally, the stadium employs seven full-time staff.

Table 1 outlines the type, amount, use, emission factors, replacement rates and end-of-life fates for the construction materials considered. The data on the source, amount and type of structural and service materials were provided by the stadium's construction company. The impacts of the construction material were amortised over 390 game days over the thirty year lifetime. This allocation approach is consistent with other greenhouse gas footprints of stadiums (Econ Pöyry AB, 2009). It is considered that the structural materials are unlikely to be 
replaced over the thirty year lifetime. Other materials, including those for services (e.g. toilet cisterns, electrical cabling) and internal fit-outs (e.g. plasterboard) are considered likely to be replaced once over the thirty year period. These lifetime assumptions are consistent with other literature (Scheuer et al., 2003). As the stadium materials will be disposed in the future, the end-of-life fate is uncertain. Given this uncertainty, materials were assumed to be in landfill or recycled at typical recycling rates (Hardie, Khan, \& Miller, 2006; Nolan-ITU, 2002; Tam, 2009). For materials coming into contact with wastewater (stormwater or sewage) it was assumed that the end-of life was landfill, except for the steel sewer mains, which represent a significant mass and thus are considered likely to be recovered for recycling.

\section{INSERT TABLE 1 HERE}

The impacts of construction activities were estimated using average emission factors for the construction of concrete structural systems, coupled with the total mass of concrete used. An average emission factor of $17.76 \mathrm{~kg} \mathrm{CO} 2$-eq per tonne of concrete was adopted, based on (Cole, 1998). The emission factor accounts for on-site equipment use, worker transportation, and equipment transport (Cole, 1998). Using this approach, construction activity emissions were estimated to be 973.0 tonne $\mathrm{CO}_{2}$-eq.

The stadium operates on a base load each day, with game-day operations adding to this base load. All data relating to the base operation of the stadium was provided by the stadium operator in disaggregated solar and grid electricity inputs, natural gas inputs (for heating of hot water), reticulated water inputs and wastewater outputs. The electricity data were disaggregated into two main 
categories: 1. requirements for chillers, refrigeration and base load lighting, and 2. ventilation. Further disaggregation of the chillers, refrigeration and base load lighting was not possible, due to these services being on the same circuit and being monitored by only one meter. The electricity inputs for base load operations were based on a mix of grid electricity from the Queensland (state) grid (80\%) and solar electricity (20\%). The stadium exports excess electricity generated, but no environmental credits were applied for the potential of exporting excess solar electricity during base load operations. The inventory for baseload operations is provided in Table 2.

\section{INSERT TABLE 2 HERE}

For game-day operations, as indicated in Table 3, there is an increase in the demand for hot water, volume of wastewater discharge, an increase in mass of solid waste generated (due to disposed food, beverage and associated packaging), and for events being held at night, an increase in electricity inputs for the stadium lighting. The water for flushing of toilets and urinals is supplied from rainwater tanks. As the stadium was only recently commissioned, no data were available on the increase in natural gas required for hot water heating, rainwater use for flushing or use of overhead stadium lighting. The natural gas impacts were allocated between the baseload and game-day load based on the amount of time and number of people attending the stadium for different purposes (person.hours). The 160,361 sporting event attendees were assumed to stay for three hours per event, equating to 481,083 person.hours. Similarly, the 5,560 event attendees were assumed to stay for three hours, equating to 16,680 person.hours. The seven fulltime staff were assumed to have worked a total of 1,824 in the calendar year, 
equating to 12,768 person.hours. The sum of these occupancies is 510,531 person.hours. Staff occupancy equates to $2.5 \%$ of the total person.hours. The 2012 gas consumption for the stadium was $18,262.5 \mathrm{~m}^{3}$. It was assumed that the hot-water use profile did not vary with the type of attendee. Baseload operations were attributed with natural gas impacts based on the $2.5 \%$ staff occupancy, equivalent to $456.7 \mathrm{~m}^{3}$ while the remainder of the natural gas consumption was attributed to game-day operations. The impacts of the natural gas used during corporate events were attributed to the sporting events, as per the system expansion procedure described earlier.

\section{INSERT TABLE 3 HERE}

Grass growing, installation, maintenance and disposal impacts were based on previous greenhouse gas studies (Carre, Crossin, \& Clune, 2013; Meil \& Bushi, 2006), with the grass from the playing surface assumed to be replaced every three years.

The disposal of wastewater on game days was estimated based on 1 flush of an 8 litre toilet cistern per attendee. Electricity inputs for stadium lighting (for night games) were calculated based on the number of light towers at the stadium (6), the number of lights per tower (estimated to be 80 ), the energy rating of typical stadium lights $(2 \mathrm{~kW})$, a $53 \%$ capacity factor for stadium lighting and an average running time of 4 hours per night event (Melbourne Cricket Ground, 2012) . Based on these assumptions, the electricity input is $2.04 \mathrm{MWh}$ per night event. The electricity input for night lighting was based on grid electricity. The total solid waste generated by spectators in 2011 was $18,945 \mathrm{~kg}$. This equates to an average of $130.4 \mathrm{~g}$ per attendee per event. The material composition of the 
solid waste was unknown. For modelling purposes, the fraction of plastic and paper (comingled), cardboard and other rubbish were based on an audit of a rugby event in New Zealand (RWC Ltd., 2008). Using the rugby event study, 54\% of waste (by mass) is comingled plastic and paper, $9 \%$ is cardboard, and $37 \%$ is undisclosed waste. The split between plastic and paper was assumed to be $28 \%$ and $72 \%$, based on municipal solid waste mixes in waste streams in Australia (DEWHA, 2010). The recycling rates were unknown, but for cardboard/paper and plastics were estimated to be $60 \%$ and $20 \%$, respectively (DEWHA, 2010). The undisclosed waste and non-recyclable materials generated by attendees were assumed to be disposed of in landfill.

All foreground data were coupled with background datasets from the Australasian Unit Process Life Cycle Inventory (Grant, 2010) and Ecoinvent 2.2 (Ecoinvent, 2007). Details of processes included and data sources are provided in Table 4 . The quality of the data varied in terms of temporal and regional relevance, however the data quality was considered appropriate to investigate the directional nature of the greenhouse gas impacts.

INSERT TABLE 5 HERE

\section{Impact assessment}

Life cycle impacts were assessed for the global warming mid-point category. The LCIA was calculated by multiplying the total emissions of the various greenhouse gases by their respective global warming potentials (GWPs), then adding the global warming equivalencies for the various greenhouse gases. GWPs were based on the IPCC 2007 global warming potentials factors for a 100 year timeframe (IPCC, 2007). The greenhouse gases assessed included carbon dioxide, 
methane, nitrous oxide, sulphur hexafluoride and the suite of hydrofluoro-carbons (HFC's) and chlorofluro-carbons (CFC's). Carbon sequestration (e.g. biogenic carbon in landfill) was not included in the impact assessment. All LCIA calculations were performed using SimaPro 7.2.4.

\section{Results}

The total greenhouse gas emissions for one person at one event was $14.74 \mathrm{~kg}$ $\mathrm{CO}_{2}$-eq. The greenhouse gas impact results, and the relative contributions of the construction materials, operation, and the end-of-life phases of the stadium, are reported in Table 5 and Figure 2.

\section{INSERT TABLE 5 HERE}

\section{INSERT FIGURE 2 HERE}

Construction impacts contributed to $3.65 \mathrm{~kg} \mathrm{CO}_{2}$-eq, or $24.7 \%$ of total life cycle greenhouse emissions. The contribution of the materials to the construction impacts are reported in Table 6, with concrete and structural steel dominating, contributing to $1.43 \mathrm{~kg} \mathrm{CO}_{2}$-eq and $1.31 \mathrm{~kg} \mathrm{CO}_{2}$-eq, respectively, equivalent to $9.7 \%$.and $8.9 \%$ of life cycle greenhouse emissions. All other construction activities, including those related to construction activity and service systems, contributed to a total of $6.1 \%$ of life cycle greenhouse emissions.

\section{INSERT TABLE 6 HERE}

The operations account for $72.5 \% \%$ of total life cycle greenhouse impacts. The contributions of the various operational processes to the greenhouse gas emissions profile are reported in Table 7 and are dominated by emissions 
associated with baseload operations, accounting for $10.12 \mathrm{~kg} \mathrm{CO}_{2}$-eq, equivalent to $68.6 \%$ of total life cycle greenhouse emissions. In particular, the operation of heating, ventilation and air conditioning (HVAC), lighting and refrigeration systems, which account for $6.58 \mathrm{~kg} \mathrm{CO}_{2}$-eq, or $44.6 \%$ of life cycle greenhouse emissions. Chiller operation during the baseload accounted for $3.29 \mathrm{~kg} \mathrm{CO}_{2}$-eq or $22.3 \%$ of life cycle greenhouse emissions. Game-day operations impacts were relatively minor to baseload operations, contributing to a total of $0.57 \mathrm{~kg} \mathrm{CO}_{2}$-eq. The largest contributor to game-day operations was water heating, with $0.25 \mathrm{~kg}$ $\mathrm{CO} 2$-eq, or $2.3 \%$ of life cycle greenhouse emissions. End of life management of the construction materials and replacement of materials contributed to less than $3 \%$ of total greenhouse emissions, with emissions of $0.22 \mathrm{~kg} \mathrm{CO}_{2}$-eq and $0.19 \mathrm{~kg}$ $\mathrm{CO}_{2}$-eq, respectively.

INSERT TABLE 7 HERE

\section{Discussion}

The $72.5 \%$ contribution of greenhouse gas impacts from the operation of the stadium are driven predominantly by emissions associated with electricity inputs for refrigeration, ventilation and lighting (61.5\% of total greenhouse gas impacts) and chillers (30.8\% of total greenhouse gas impacts). As these systems operate continuously, the electricity inputs for one event are effectively an accumulation of the base-load electricity inputs (when events are not held at the stadium), as well as the additional game-day operational inputs. Electricity inputs for the examined stadium accumulate to 399.2 MWh per game day, equating to an average electricity intensity of $14.66 \mathrm{kWh}$ per person per event (for 2012 attendance figures). 
Electricity intensity values are highly sensitive to attendance rates; as such, when making comparisons with other stadiums, the electricity intensity should be normalised based on a fixed attendance rate. At maximum (100\%) capacity the electricity intensity of the AFL stadium of this study equates to 6.8 $\mathrm{kWh}$ per person per event.

There exists only one study which assesses electricity intensity across a number of different stadiums (Econ Pöyry AB, 2009). Figure 3 plots electricity intensity versus stadium size for data from this study, assuming $100 \%$ attendance. The Econ Pöyry study utilised a process-based LCA methodology to assess the greenhouse gas emissions associated with the hosting of the 2010 FIFA World Cup. The Econ Pöyry study includes projections of electricity use for each stadium utilised during the event. In Figure 3, most stadiums have an electricity intensity of between $4.0 \mathrm{kWh}$ and $4.5 \mathrm{kWh}$ per person per event, approximately $65 \%$ of the intensity for that of the AFL stadium.

\section{INSERT FIGURE 3 HERE}

Stadiums are unique in that they experience large surges in occupancy over a short period of time. These large variations in occupancy can be problematic for refrigeration and HVAC systems and electrical systems more broadly. Indeed, the operator of the stadium under study indicated that the continuous operation of the stadiums refrigeration, HVAC and chilling systems was necessary to avoid overloading electrical circuits during peak demand (e.g. during an event). The continual operation of the refrigeration, HVAC and chilling systems in this study could partly explain the high electricity intensity, relative to other stadiums. In addition, the stadium under study had only been in operation 
for one year and the operation may not have been optimised. Finally, thermal loads placed on the HVAC systems in the case-study stadium may have been higher than for those studies by Econ Pöyry, e.g. due to climatic variations.

In the review of the electricity intensity of the South African stadiums, the Moses Mabhida stadium is particularly important, with an intensity of $2.77 \mathrm{kWh}$ per person per event, a $37 \%$ reduction relative to the average of the other South African stadiums. This reduction is driven by a number of design interventions, including the utilisation of natural ventilation and lighting, and heat pumps for water heating. Importantly, the Moses Mabhida stadium utilises systems which can be selectively switched off locally, thereby reducing base-load energy requirements by $20 \%$ (UEMP, 2010). This feature is in contrast to the stadium in this study, where the base-load systems operate continuously. Addressing the continual operation of systems in the case-study stadium presents a significant opportunity to reduce the greenhouse gas emissions associated with operation of the stadium.

Compared with the operations phase, the environmental impacts associated with the stadium construction are relatively minor (24.7\%). These construction greenhouse gas impacts are dominated by structural steel $(8.9 \%)$ and concrete $(9.7 \%)$. The emissions associated with concrete may be reduced by replacing general purpose cement within the concrete with supplementary cementetious materials, such as ground-granulated blast furnace slag, which have been shown to offer greenhouse gas reductions of between $22 \%$ and $40 \%$ (Flower \& Sanjayan, 2007; Heidrich, Hinczak, \& Ryan, 2005). 


\section{Limitations}

One aim of this study was to investigate the material and energy processes which drive the greenhouse gas emissions associated with the construction, operation and end-of-life of a stadium. This assessment included a quantification of the total greenhouse gas emissions associated with attendance at a sporting event. This quantification has a number of important limitations, which are likely to affect the overall magnitude of the greenhouse gas impacts of attending a sporting match.

\section{Exclusion of travel}

The transportation of the spectators to the venue was not included in this life cycle assessment. It is recognised that spectator transport can be a significant contributor to greenhouse gas emissions. Econ Pöyry estimate that spectator transport can contribute to more than $85 \%$ of total greenhouse gas impacts (2009), but this was for an international sporting event, rather than a domestic sporting event. Similarly, attendee travel was estimated to account for $87 \%$ of Live Earth concerts (Live Earth, 2007), held at seven different stadiums. Interestingly, only $2 \%$ of the attendees travelled by air, yet they contributed to $80 \%$ of greenhouse gas emissions (Live Earth, 2007). In this respect, estimations of greenhouse gas emissions associated with attendee travel are highly sensitive to the number travelling by air. No literature was available on attendee travel behaviour for AFL matches in Australia, or indeed for any sporting code in Australia. Given that there are likely to be at least some spectators using air travel, it is highly likely that attendee travel would contribute to a significant proportion of greenhouse gas emissions. Data surveys on domestic spectator travel behaviour are warranted and 
would need to be undertaken to investigate and quantify the significance of this on environmental impacts.

\section{Partition methodology}

The default assumption in this study was that stadium construction, operation and demolition impacts were wholly attributable to attendees at sporting events, and those attending corporate events received no environmental burden. It could be argued that some of these impacts should be attributable to those attending corporate events at the stadium. A number of alternative partitioning approaches may be used to allocate the life cycle impacts across all patrons, including methods based on attendance values, or methods accounting for revenue (economic allocation). Given that $96.6 \%$ of attendance was for sporting events, and $3.4 \%$ was for corporate events, partitioning using one of the alternate approaches would reduce the magnitude of the sport-event based greenhouse gas values, but would not alter the dominant processes contributing to the environmental impacts.

\section{Stadium lifetime and attendance}

The default assumption in this study was that the greenhouse emissions associated with construction and end of life material waste management were amortised equally over a total attendance of approximately 4.81 million people over the 390 events over thirty years. Should the total number of attendees increase over this period, then the greenhouse gas emissions associated with construction and end of life will decrease. For example, if the average attendance increased to 20,000 per event (approximately 80\% capacity), the contribution from construction impacts 
would be diluted from $3.65 \mathrm{~kg} \mathrm{CO}_{2}$-eq to $2.25 \mathrm{~kg} \mathrm{CO}_{2}$-eq. Likewise, should the life expectancy be extended beyond thirty years, then the greenhouse gas emissions associated with construction and end of life will decrease. The changes in construction and end of life impacts may not be linear, due to different material replacement requirements.

The greenhouse gas emissions profile presented is based on an average patronage for one year and total energy and material flows for one years' operation. Given that the patronage during that year varied from 5,150 people to 16,550 people, it might be expected that the greenhouse gas emissions profile would change with attendance. The aggregated nature of the operational data provided meant that energy and material requirements for different attendances, including marginal increases in energy/material requirements per spectator, could not be acquired nor determined. Nevertheless, it would be expected that the greenhouse gas emissions from operations attributed to an individual's attendance would vary, depending on the total attendance.

\section{Exclusion of upstream processes associated with construction activity}

This study utilised process-based LCA and did not incorporate any economic input-output LCA (EIO-LCA) modelling. The use of economic input-output LCA, coupled with process-based LCA can provide a broader system boundary to provide a more comprehensive assessment by including economic activity not readily captured by process-based LCA, such as the impacts associated with engineering services. The stadium was completed in 2010, costing AU\$144.2 million. A preliminary EIO-LCA assessment was performed using the Australian 2008-09 EIO database (Grant, 2013), assuming that the economic activity was 
attributable to the non-residential building construction economic sector. An annual inflation rate of $2.7 \%$ between 2008-09 and 2009-10 (ABS, 2012) was used to adjust the construction cost to 2008-09 values (AU\$140.4 million). The same impact assessment method as for the process-based LCA was used. Using this approach, the stadium construction impacts were 56,783.32 tonne $\mathrm{CO}_{2}$-eq; approximately three times the impacts of the $16,503.3$ tonne $\mathrm{CO}_{2}$-eq derived using the process-LCA approach. The scale of the difference between the two methods is consistent with other comparisons between process- and EIO-based LCAs (Crawford, 2008). This preliminary EIO-LCA assessment suggests that the inclusion of other economic activities would increase the impacts of the stadium construction.

\section{Conclusion}

This paper presents an inventory and assessment of the life cycle greenhouse gas impacts of an Australian Football League stadium, using a process-based LCA approach. The greenhouse gas impacts were determined to be $14.74 \mathrm{~kg} \mathrm{CO}_{2}$-eq per person per event based on the system boundary and analysis presented. These impacts are likely to be higher should the system boundary be expanded to include attendee travel and other upstream economic activities, or if assumptions regarding attendance and stadium life expectancy vary. The operation of the stadium contributed to the majority of life cycle greenhouse gas emissions, accounting for $72.5 \%$ of total emissions. The operational impacts were mostly driven by emissions associated with continually-operating electrical baseload refrigeration, HVAC and lighting equipment. The continual operation of these systems was necessary so as to not overload electrical circuits during changes in 
peak/off-peak demand. Allowing for intermittent operation of these systems may present the greatest opportunity to reduce the greenhouse gas impacts over the life cycle of the stadium. These conclusions reinforce the importance and relevance of future research into the design of stadium for efficient operation and thereby reduction of environmental impacts.

\section{Acknowledgement}

[--- removed for double-blind process --- ]

\section{References}

ABS. (2012). Consumer Price Index. Australia. December Quarter 2011. Canberra: Australian Bureau of Statistics.

Austadiums Website. (2013). Crowds. Retrieved 18/01/2013 http://www.austadiums.com/sport/crowds.php

Aye, L., Ngo, T., Crawford, R. H., Gammampila, R., \& Mendis, P. (2012). Life cycle greenhouse gas emissions and energy analysis of prefabricated reusable building modules. Energy and Buildings, 47, 159-168.

Blanchard, S., \& Reppe, P. (1998). Life Cycle Analysis of a Residential Home in Michigan. University of Michigan, Ann Arbor.

Blengini, G. A. (2009). Life cycle of buildings, demolition and recycling potential: A case study in Turin, Italy. Building and Environment, 44(2), 319-330.

Carre, A. (2010). A Comparative Life Cycle Assessment of Alternative Constructions of a Typical Australian House Design Melbourne: Forest \& Wood Products Australia Limited.

Carre, A., Crossin, E., \& Clune, S. (2013). LCA of Kerbside Recycling in Victoria. Report for Sustainability Victoria. Melbourne: RMIT University.

Cole, R. J. (1998). Energy and greenhouse gas emissions associated with the construction of alternative structural systems. Building and Environment, 34(3), 335-348.

Collins, A., Flynn, A., Munday, M., \& Roberts, A. (2007). Assessing the environmental consequences of major sporting events: the 2003-04 FA Cup Final. Urban Studies, 44(3), 457-476.

Crawford, R. H. (2008). Validation of a hybrid life-cycle inventory analysis method. Journal of Environmental Management, 88(3), 496-506.

DEWHA. (2010). National Waste Report 2010. Australian Government. Department of the Environment, Water, Heritage and the Arts.

Ecoinvent. (2007). Ecoinvent data v2.2. Switzerland: Swiss Centre for Life Cycle Inventories. 
Econ Pöyry AB. (2009). Feasibility Study For A Carbon Neutral 2010 FIFA World Cup In South Africa. Stockholm: Econ Pöyry AB.

FIFA. (2013). FIFA World Cup Brasil. Sustainability. Summary of the 2014 FIFA World Cup Brazil Carbon Footprint: Fédération Internationale de Football Association, 2014 FIFA World Cup Organising Committee Brazil, MGM Innova do Brasil Ltda.

Finnveden, G., Hauschild, M. Z., Ekvall, T., Guinée, J., Heijungs, R., Hellweg, S., ... Suh, S. (2009). Recent developments in Life Cycle Assessment. Journal of Environmental Management, 91(1), 1-21.

Flower, D., \& Sanjayan, J. (2007). Green house gas emissions due to concrete manufacture. The International Journal of Life Cycle Assessment, 12(5), 282-288.

Grant, T. (2001). The Olympic stadium analysed using the DPWS tool. Retrieved 02 October 2012, from http://intro2sportsarchitecture.files.wordpress.com/2011/05/stadiumaustral ialca1.pdf

Grant, T. (2010). Australasian Unit Process Life Cycle Inventory. Published by Life Cycle Strategies Pty Ltd, Melbourne.

Grant, T. (2013). Australia Input Output 2008-09 greenhouse gas database. Published by Life Cycle Strategies Pty Ltd, Melbourne.

Hardie, M., Khan, S., \& Miller, G. (2006). Waste minimisation in office refurbishment projects : an Australian perspective. eprints.qut.edu.au/27532/1/27532.pdf

Heidrich, C., Hinczak, I., \& Ryan, B. (2005). SCM's potential to lower Australia's greenhouse gas emissions profile. Paper presented at the Australasian Slag Association Conference, Sydney.

IBISWorld Pty Ltd. (2013a). IBISWorld Industry Report H4401. Hotels and Resorts in Australia.

IBISWorld Pty Ltd. (2013b). IBISWorld Industry Report H4510. Pubs, Bars and Nightclubs in Australia.

IPCC. (2007). Climate Change 2007: The Physical Science Basis. Cambridge: Cambridge University Press.

ISO. (2006). ISO 14040:2006(E) Environmental management - Life cycle assessment - Principles and framework. Geneva: International Organization for Standardization.

Junnila, S., \& Horvath, A. (2003). Life-Cycle Environmental Effects of an Office Building. Journal of Infrastructure Systems, 9(4), 157-166.

Junnila, S., Horvath, A., \& Guggemos, A. (2006). Life-Cycle Assessment of Office Buildings in Europe and the United States. Journal of Infrastructure Systems, 12(1), 10-17.

Kofoworola, O., \& Gheewala, S. (2008). Environmental life cycle assessment of a commercial office building in Thailand. The International Journal of Life Cycle Assessment, 13(6), 498-511.

Lenzen, M. (2000). Errors in Conventional and Input-Output—based Life-Cycle Inventories. Journal of Industrial Ecology, 4(4), 127-148.

Li, Z. (2006). A new life cycle impact assessment approach for buildings. Building and Environment, 41(10), 1414-1422. 
Live Earth. (2007). Live Earth Carbon Assessment \& Footprint Report. Beverly Hills: Live Earth, LLC.

LOC. (2010). London 2012. Carbon footprint study - Methodology and reference footprint: London Organising Committee of the Olympic Games and Paralympic Games Ltd, .

Meil, J., \& Bushi, L. (2006). Estimating the Required Global Warming Offsets to Achieve a Carbon Neutral Synthetic Field Turf System Installation: Athena Institute.

Melbourne Cricket Ground. (2012). MCG Light Towers. Retrieved 04 October 2012, from http://www.mcg.org.au/The\%20MCG\%20Stadium/Facts\%20and $\% 20$ Figu res/Light $\% 20$ Towers.aspx? $\mathrm{p}=1 \& \mathrm{Q}=$

Nolan-ITU. (2002). Recycling - How Does Australia Compare? : Nolan-ITU Pty Ltd.

Norman, J., MacLean, H., \& Kennedy, C. (2006). Comparing High and Low Residential Density: Life-Cycle Analysis of Energy Use and Greenhouse Gas Emissions. Journal of Urban Planning and Development, 132(1), 1021.

Ochoa, L., Hendrickson, C., \& Matthews, H. (2002). Economic Input-output Lifecycle Assessment of U.S. Residential Buildings. Journal of Infrastructure Systems, 8(4), 132-138.

RWC Ltd. (2008). Case Study - Reducing the environmental impact of sporting events in stadia: Rugby World Cup Limited.

Sartori, I., \& Hestnes, A. G. (2007). Energy use in the life cycle of conventional and low-energy buildings: A review article. Energy and Buildings, 39(3), 249-257.

Scheuer, C., Keoleian, G. A., \& Reppe, P. (2003). Life cycle energy and environmental performance of a new university building: modeling challenges and design implications. Energy and Buildings, 35(10), 10491064.

Suzuki, M., \& Oka, T. (1998). Estimation of life cycle energy consumption and CO2 emission of office buildings in Japan. Energy and Buildings, 28(1), $33-41$

Tam, V. W. Y. (2009). Comparing the implementation of concrete recycling in the Australian and Japanese construction industries. Journal of Cleaner Production, 17(7), 688-702.

Treloar, G. J., Love, P. E. D., Faniran, O. O., \& Iyer-Raniga, U. (2000). A hybrid life cycle assessment method for construction. Construction Management and Economics, 18(1), 5-9.

UEMP. (2010). 2010 FIFA World Cup. Moses Mabhida Stadium. Environmental performance enhanced: Urban Environmental Management Programme.

Weidema, B. P. (2001). Avoiding Co-Product Allocation in Life-Cycle Assessment. Journal of Industrial Ecology, 4(3), 11-33.

Weidema, B. P. (2003). Market information in life cycle assessment. 


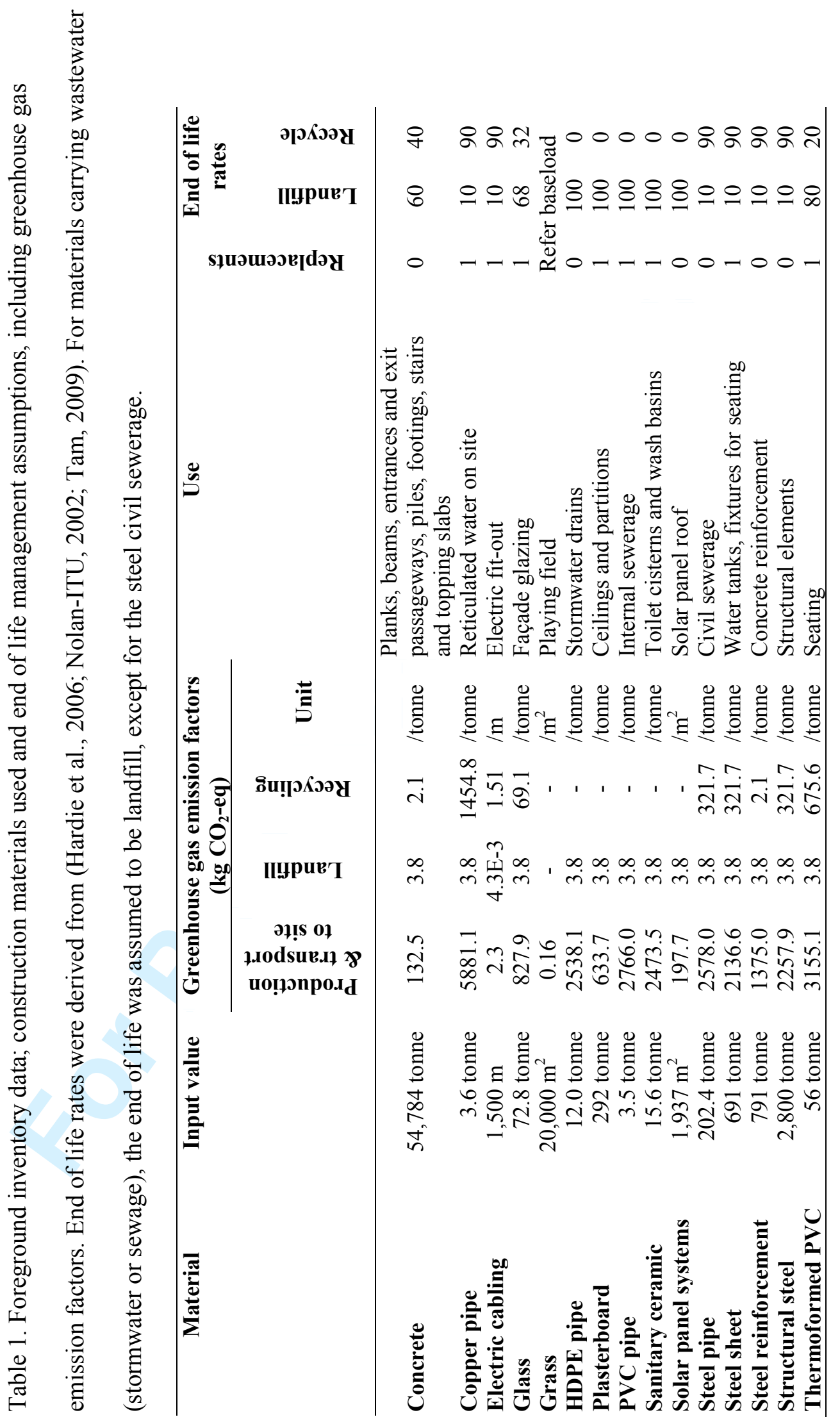




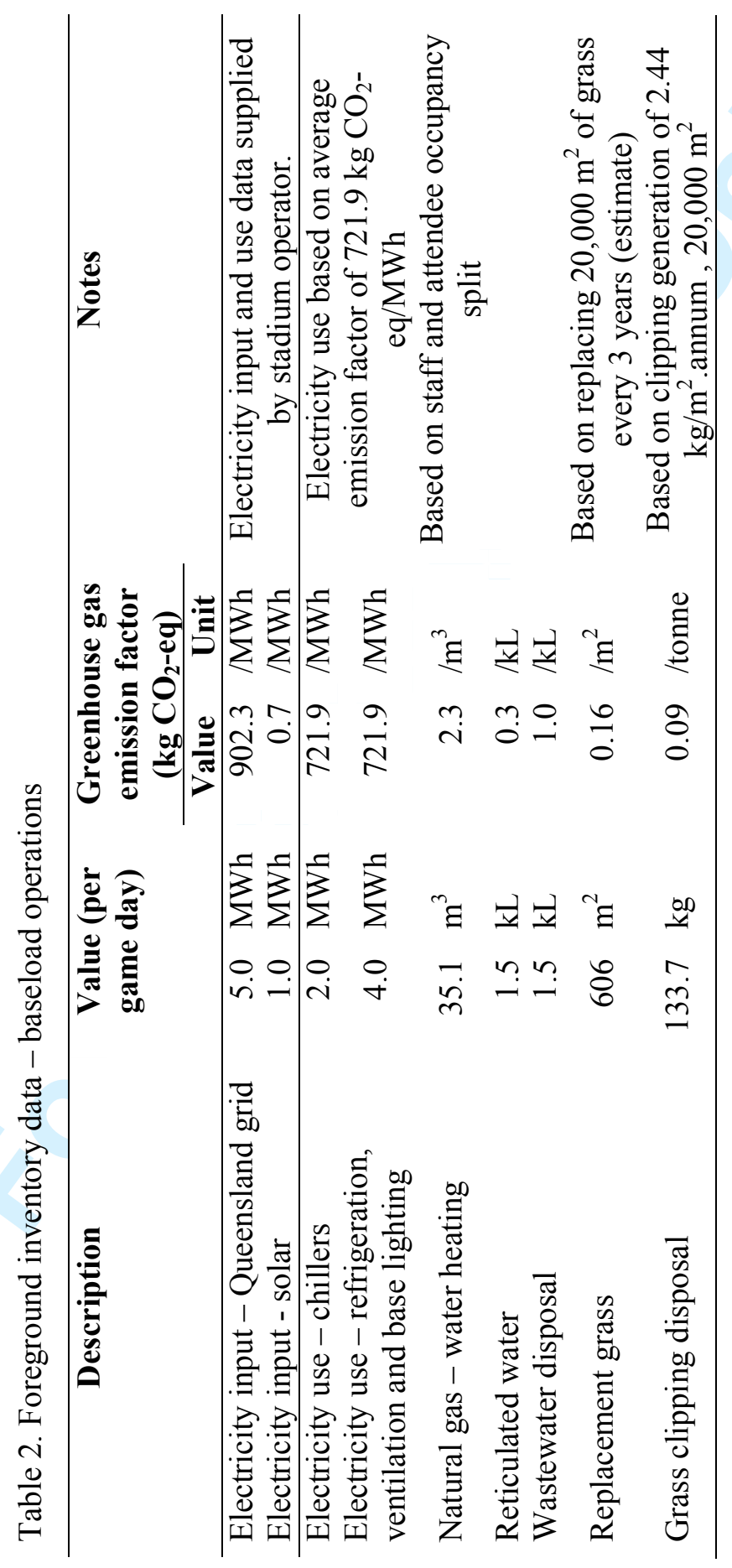




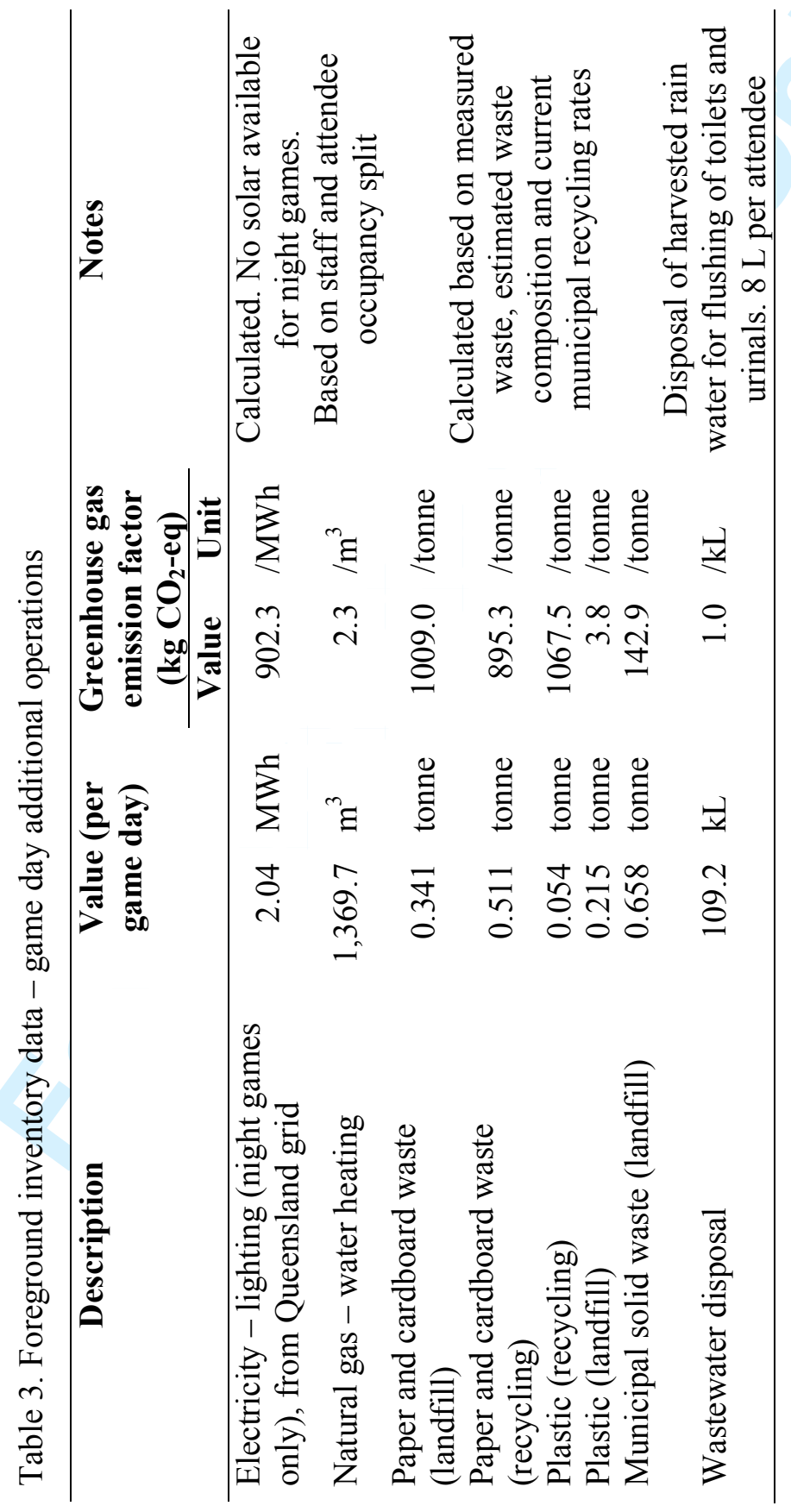




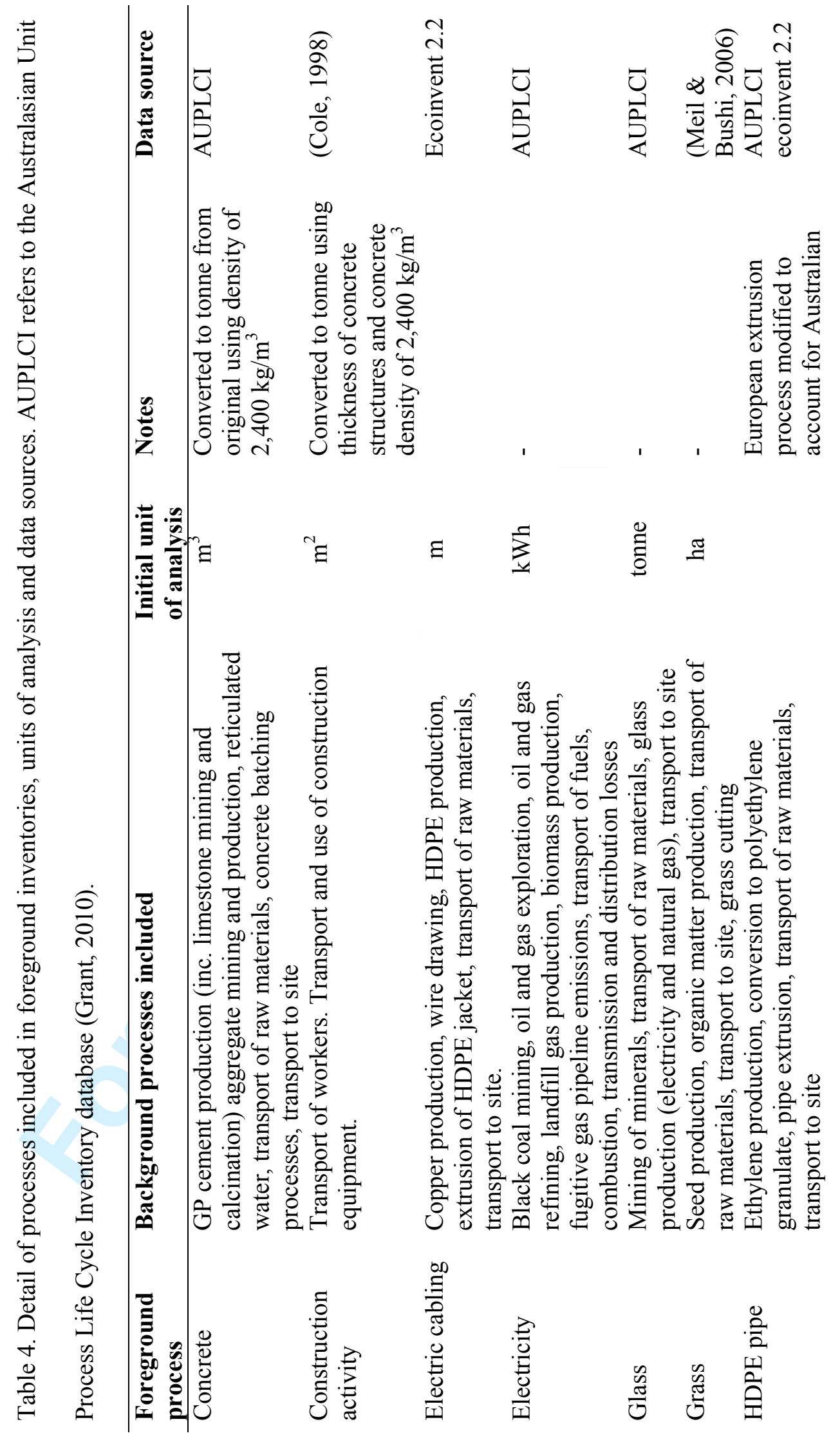




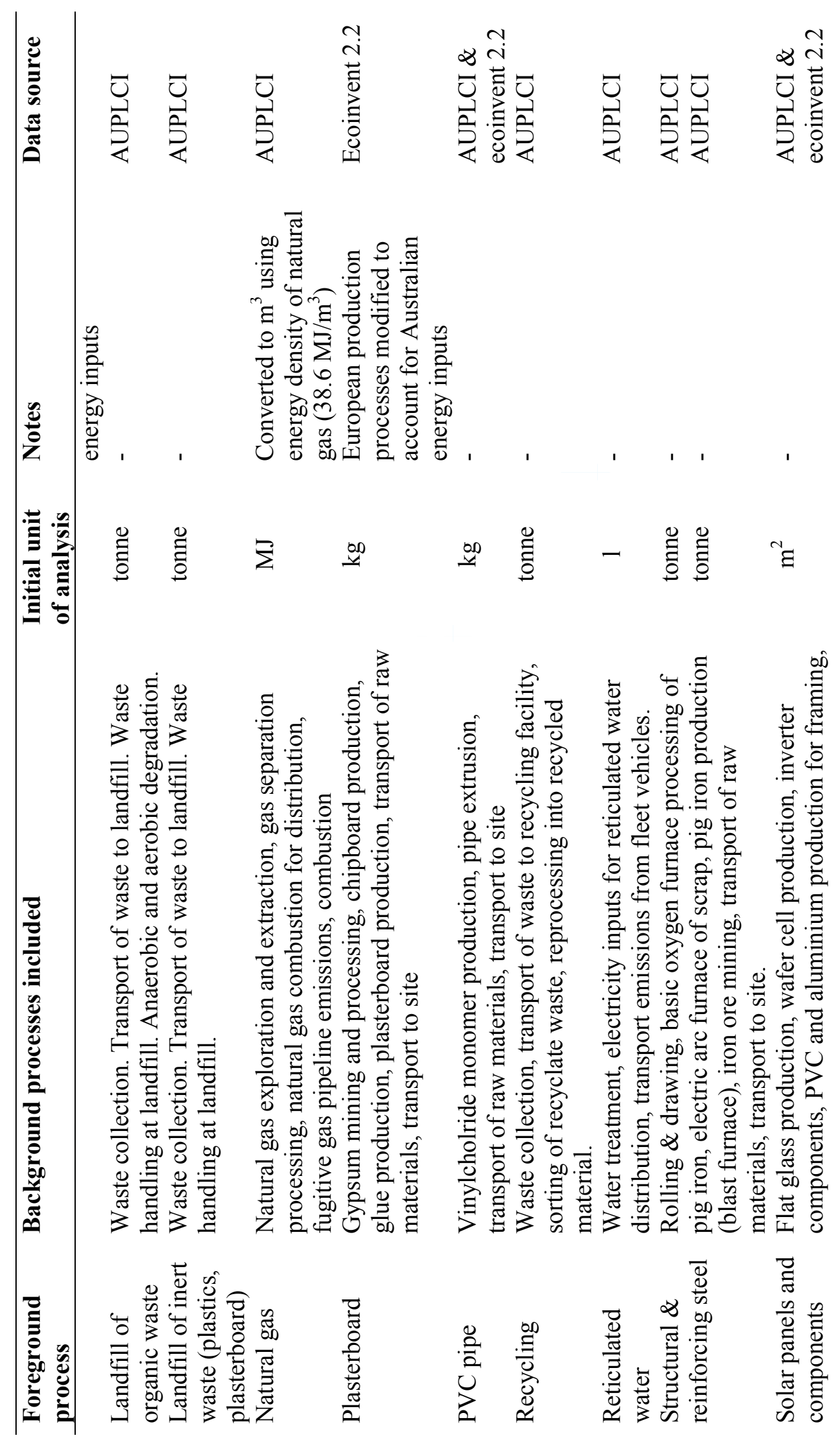




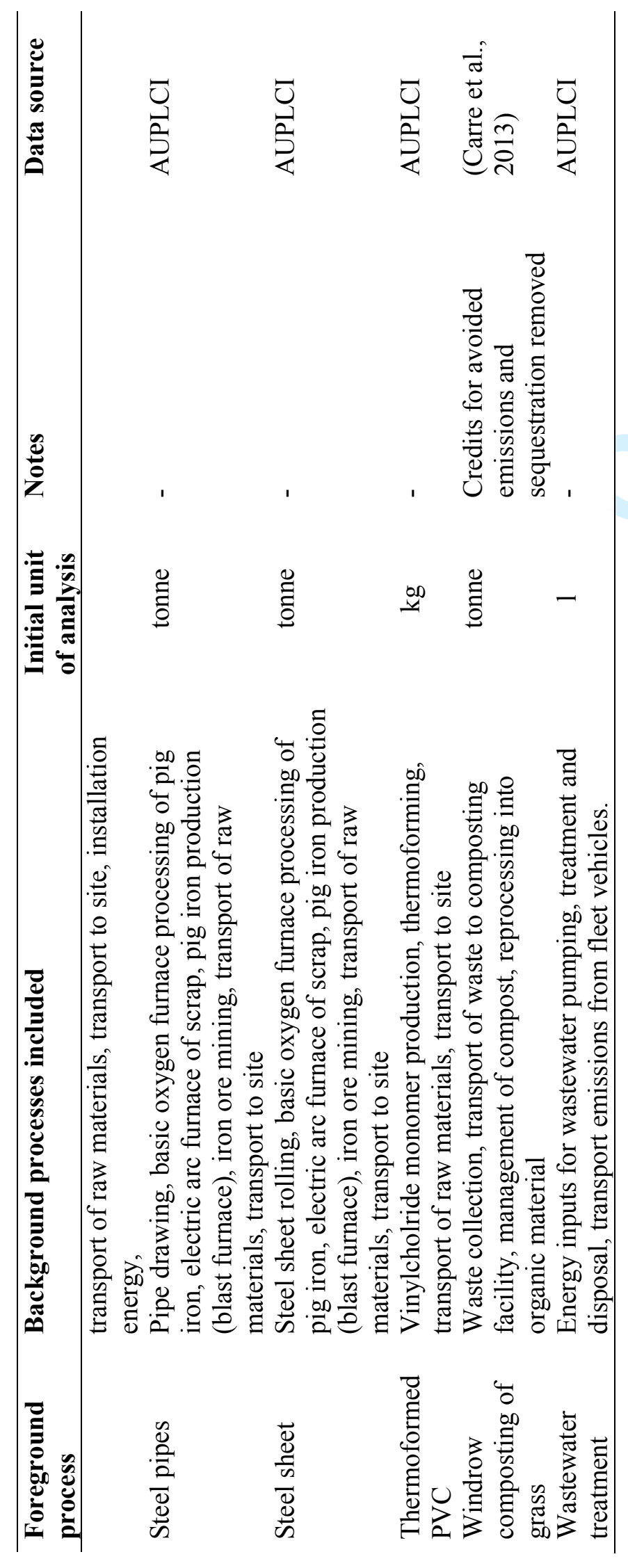


Table 5. Life cycle impact assessment results. Results are reported against the attendance of one person at one AFL event.

\begin{tabular}{lcc}
\hline Life cycle stage & $\begin{array}{c}\text { Greenhouse gas } \\
\text { emissions } \\
(\mathbf{k g ~ C O} \text {-eq) }\end{array}$ & $\begin{array}{c}\text { Contribution to } \\
\text { life cycle stage } \\
(\%)\end{array}$ \\
\hline Construction & 3.65 & 24.7 \\
Base load operations & 10.12 & 68.7 \\
Game day operations & 0.57 & 3.8 \\
Replacement materials & 0.22 & 1.5 \\
$\begin{array}{l}\text { End of life (construction and } \\
\text { replacement materials) }\end{array}$ & 0.19 & 1.3 \\
\hline Total & 14.74 & 100 \\
\hline
\end{tabular}


Table 6. Construction materials impact assessment results. Results are reported against the attendance of one person at one AFL event.

\begin{tabular}{lccc}
\hline Material / process & $\begin{array}{c}\text { Greenhouse gas } \\
\text { emissions } \\
\text { (kg CO2-eq) }\end{array}$ & $\begin{array}{c}\text { Proportion of } \\
\text { construction } \\
\text { impacts } \\
\mathbf{( \% )}\end{array}$ & $\begin{array}{c}\text { Proportion } \\
\text { of } \\
\text { total impacts } \\
\mathbf{( \% )}\end{array}$ \\
\hline Concrete & 1.43 & $39.3 \%$ & $9.7 \%$ \\
Structural steel & 1.31 & $35.9 \%$ & $8.9 \%$ \\
Reinforcing steel & 0.23 & $6.2 \%$ & $1.5 \%$ \\
Construction activity & 0.20 & $5.5 \%$ & $1.4 \%$ \\
Plumbing & 0.13 & $3.5 \%$ & $0.9 \%$ \\
Solar systems & 0.09 & $2.5 \%$ & $0.6 \%$ \\
Steel sheet & 0.08 & $2.3 \%$ & $0.6 \%$ \\
Transport of & 0.08 & $2.2 \%$ & $0.5 \%$ \\
materials & 0.04 & $1.1 \%$ & $0.3 \%$ \\
Thermoformed PVC & 0.04 & $1.0 \%$ & $0.2 \%$ \\
Plasterboard & 0.01 & $0.3 \%$ & $0.1 \%$ \\
Glass & $6.61 \mathrm{E}-04$ & $<0.1 \%$ & $<0.1 \%$ \\
New grass & $7.30 \mathrm{E}-04$ & $<0.1 \%$ & $<0.1 \%$ \\
Electrical cabling & 3.65 & $100.0 \%$ & $24.7 \%$ \\
\hline Total & & & \\
\hline
\end{tabular}


Table 7. Operation impact assessment results. Results are reported against the attendance of one person at one AFL event.

\begin{tabular}{lccc}
\hline Material & $\begin{array}{c}\text { Greenhouse } \\
\text { gas } \\
\text { emissions } \\
\text { (kg CO } \mathbf{2}^{-}\end{array}$ & $\begin{array}{c}\text { Proportion of } \\
\text { operations } \\
\text { impacts } \\
\mathbf{( \% )}\end{array}$ & $\begin{array}{c}\text { Proportion } \\
\text { of } \\
\text { total } \\
\text { impacts } \\
\mathbf{( \% )}\end{array}$ \\
\hline $\begin{array}{l}\text { Baseload - refrigeration, } \\
\text { ventilation and lighting }\end{array}$ & 6.58 & 61.5 & 44.6 \\
Baseload - chillers & 3.29 & 30.8 & 22.3 \\
Baseload - Grass maintenance & 0.25 & 2.3 & 1.7 \\
and disposal & & & $<0.1$ \\
Baseload - water heating & 0.01 & 0.1 & $<0.1$ \\
Baseload - wastewater & 0.003 & 0.02 & 68.6 \\
\hline Total baseload & 10.12 & 94.7 & 1.7 \\
\hline Game day - stadium lighting & 0.25 & 2.3 & 1.6 \\
Game day - waste management & 0.23 & 2.2 & 0.5 \\
Game day - water heating & 0.08 & 0.7 & 0.1 \\
Game day - wastewater & 0.01 & 0.1 & 3.8 \\
treatment & & & 72.5 \\
\hline Total game day & 0.57 & 5.3 & \\
\hline Total & 10.69 & 100.0 & \\
\hline
\end{tabular}


Figure 1. System boundary for streamlined assessment on stadium. Shared processes are shaded in grey

Figure 2. Life cycle greenhouse gas impacts. Results are reported per person, per event.

Figure 3. Electricity intensity for 2010 FIFA World Cup stadiums in South Africa (Econ Pöyry AB, 2009). The Moses Mabhida stadium (circled) has lower electricity intensity than the other stadium, instigated through a number of energy reduction intervention strategies. 
Figure 1. System boundary for life cycle assessment of stadium.

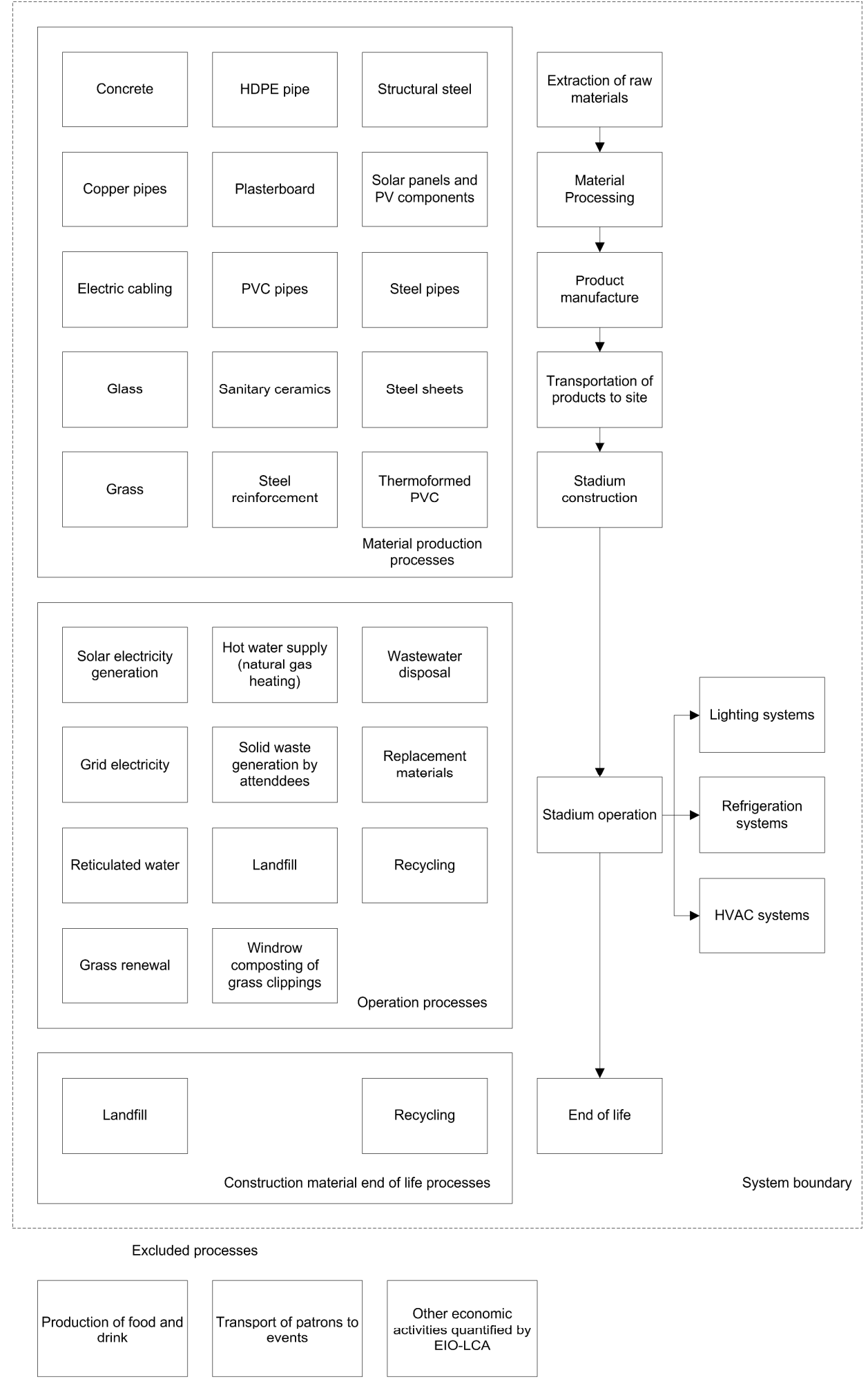


Figure 2. Life cycle greenhouse gas impacts. Results are reported per person, per event.

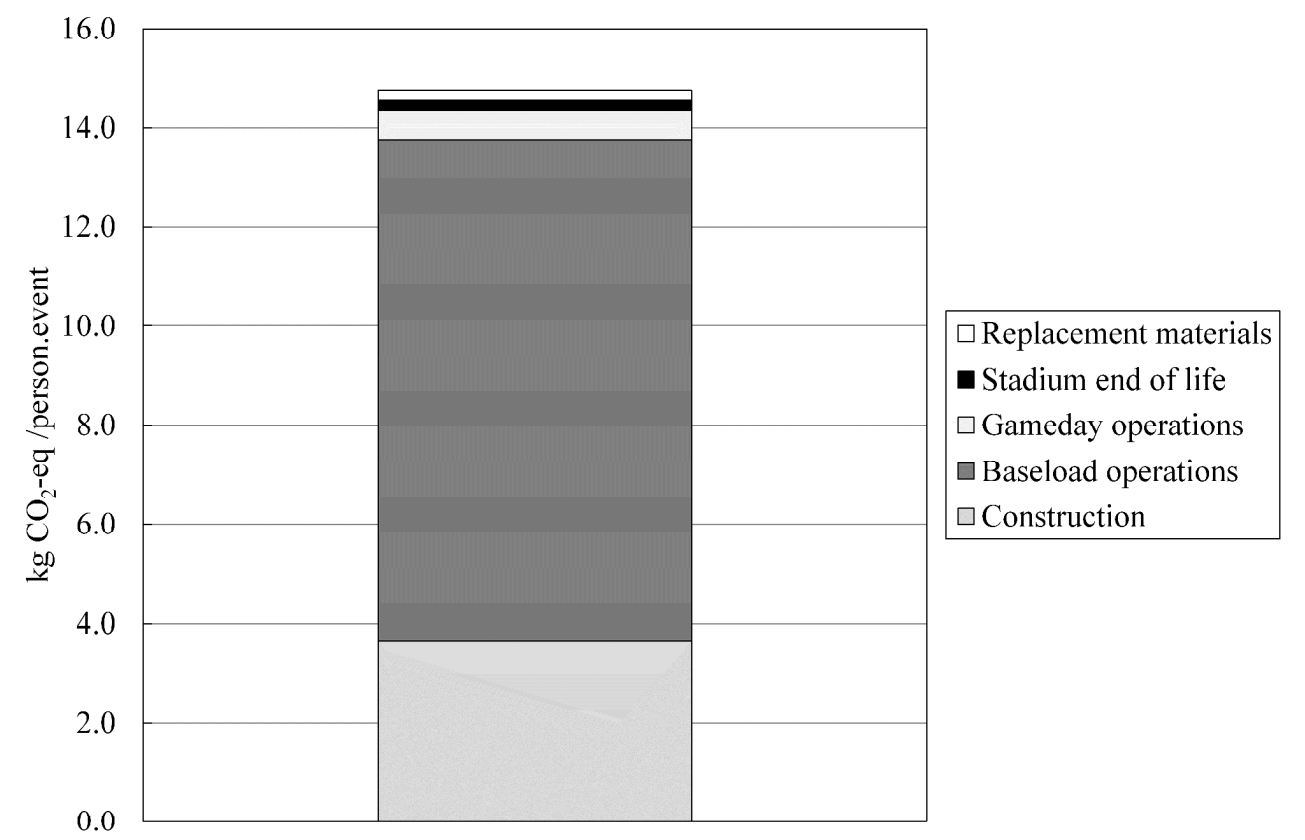


Figure 3. Electricity intensity for 2010 FIFA World Cup stadiums in South Africa (Econ Pöyry AB, 2009). The Moses Mabhida stadium (circled) has lower electricity intensity than the other stadium, instigated through a number of energy reduction intervention strategies.

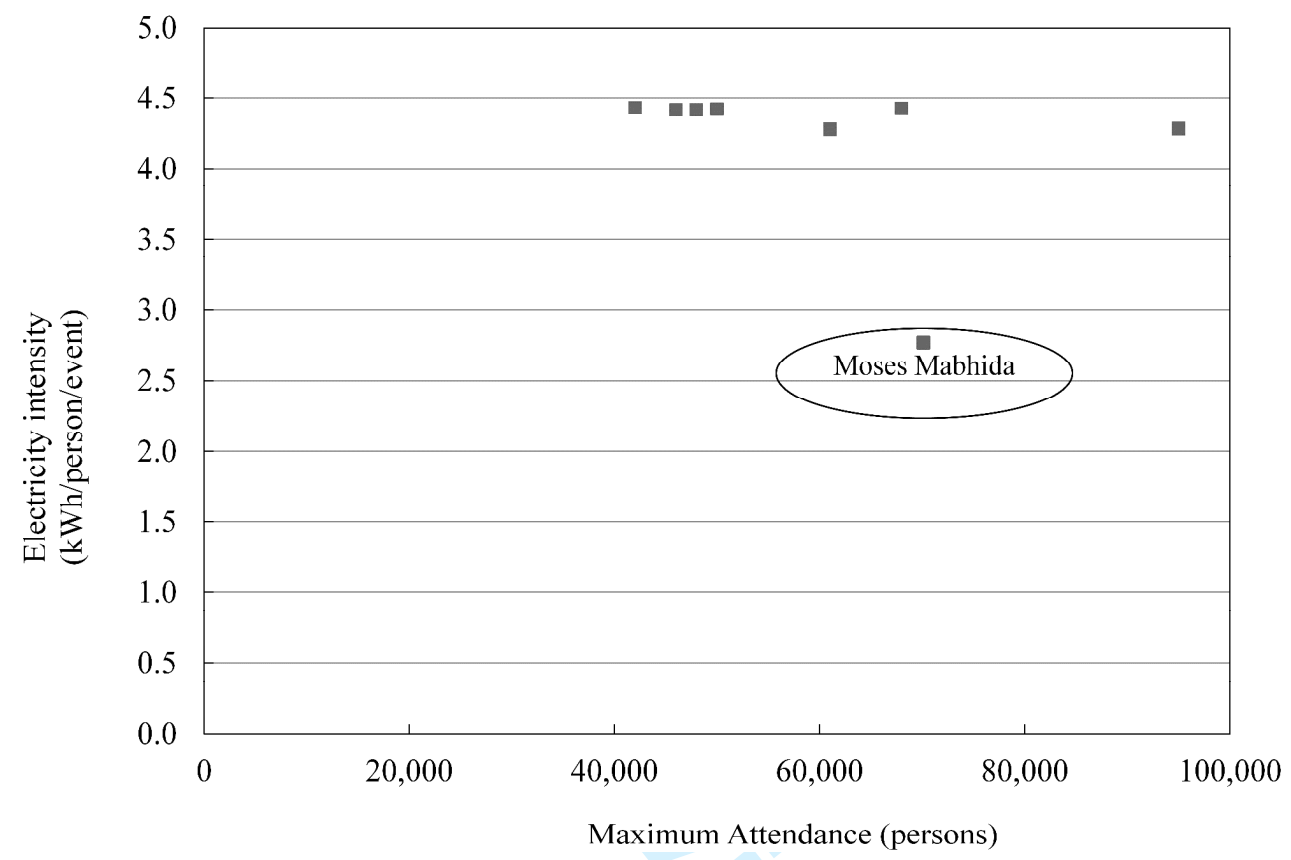




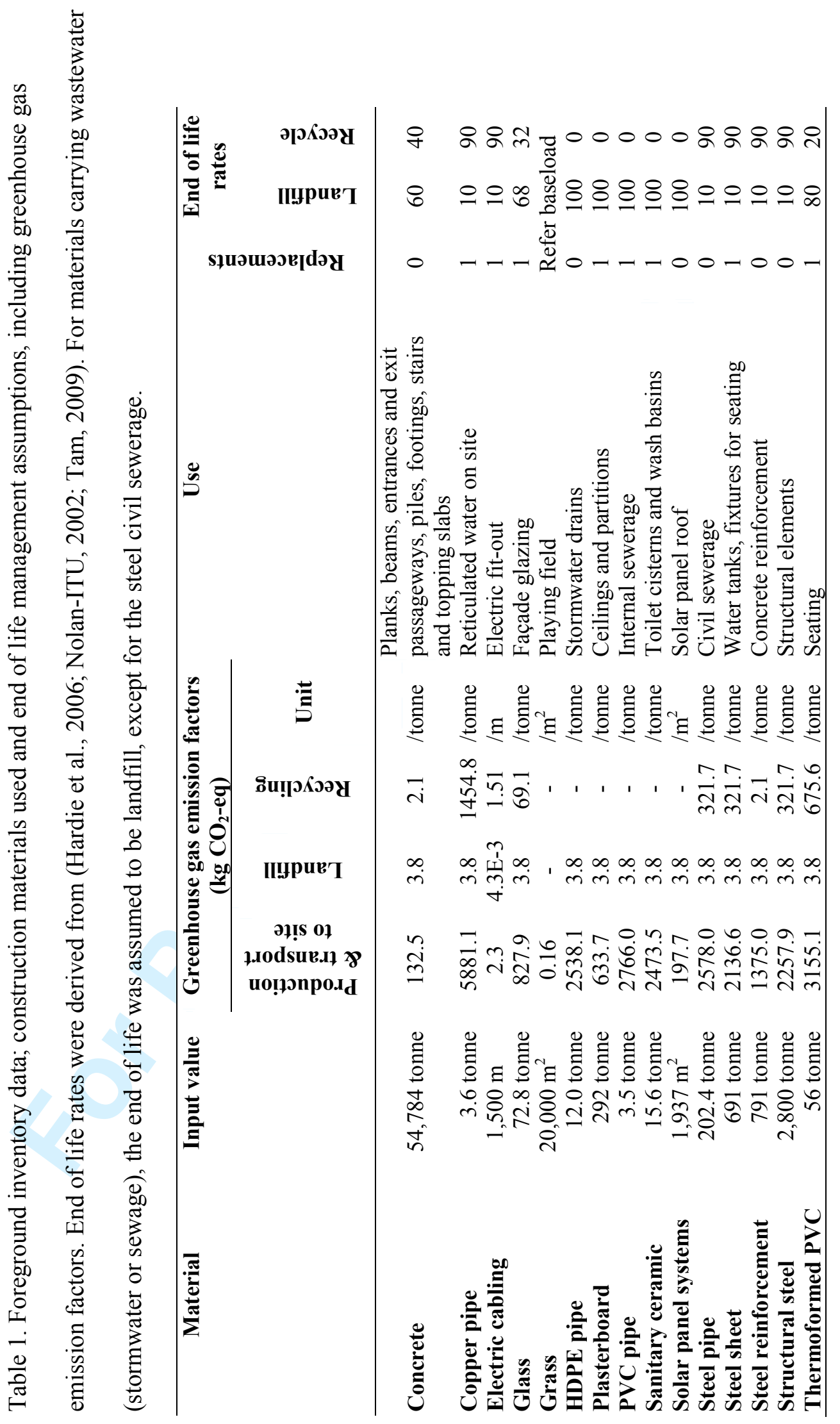




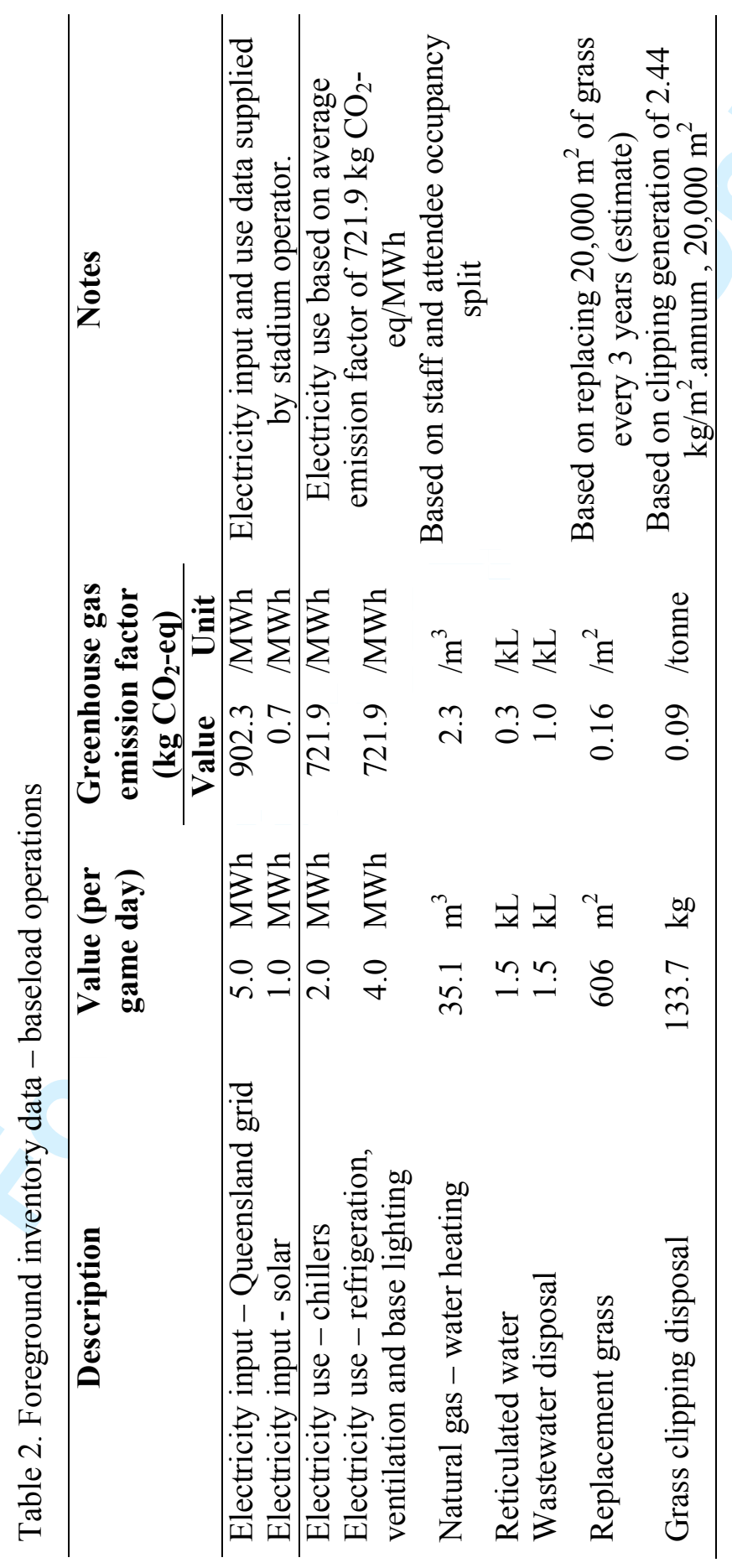




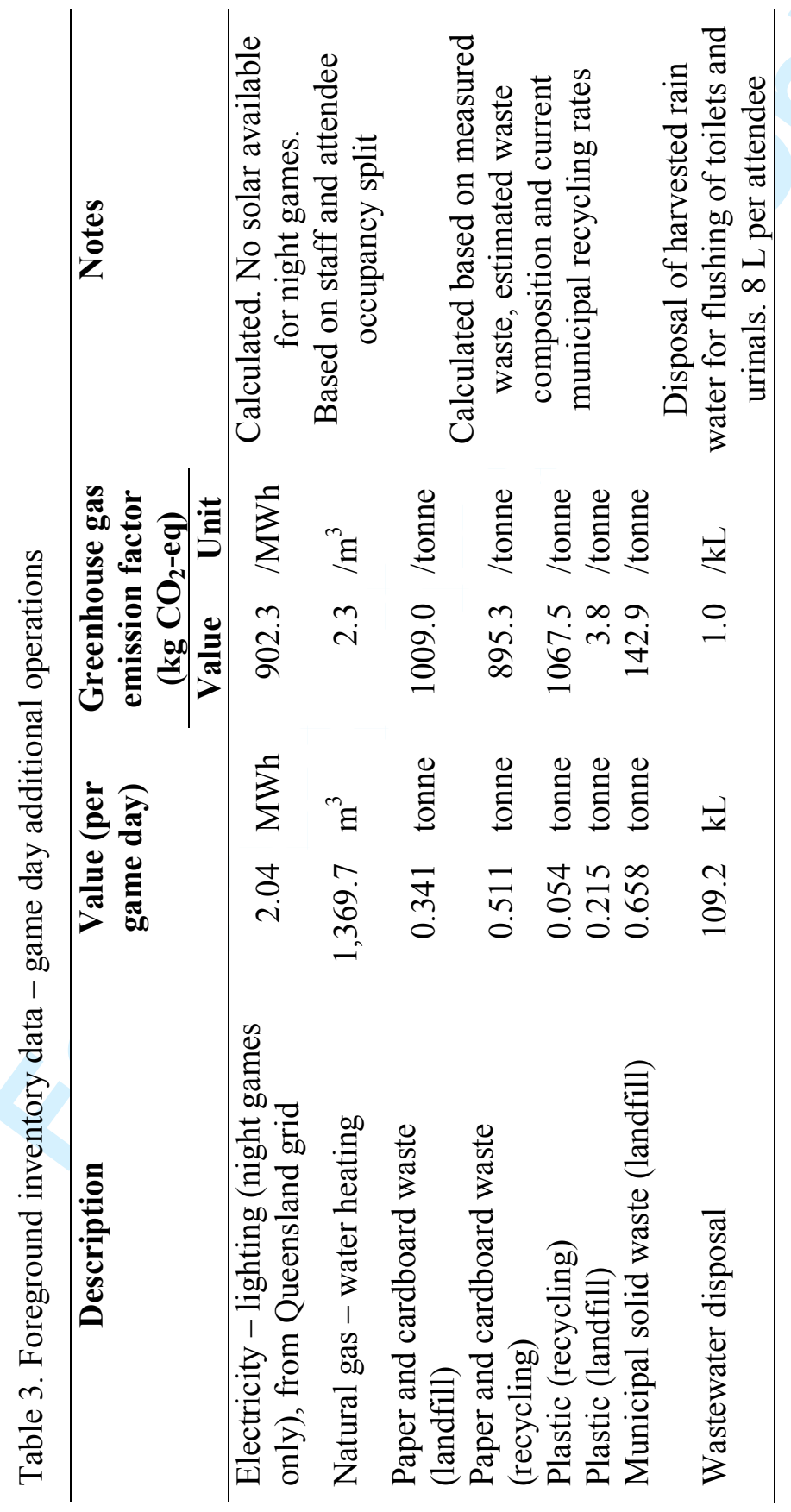




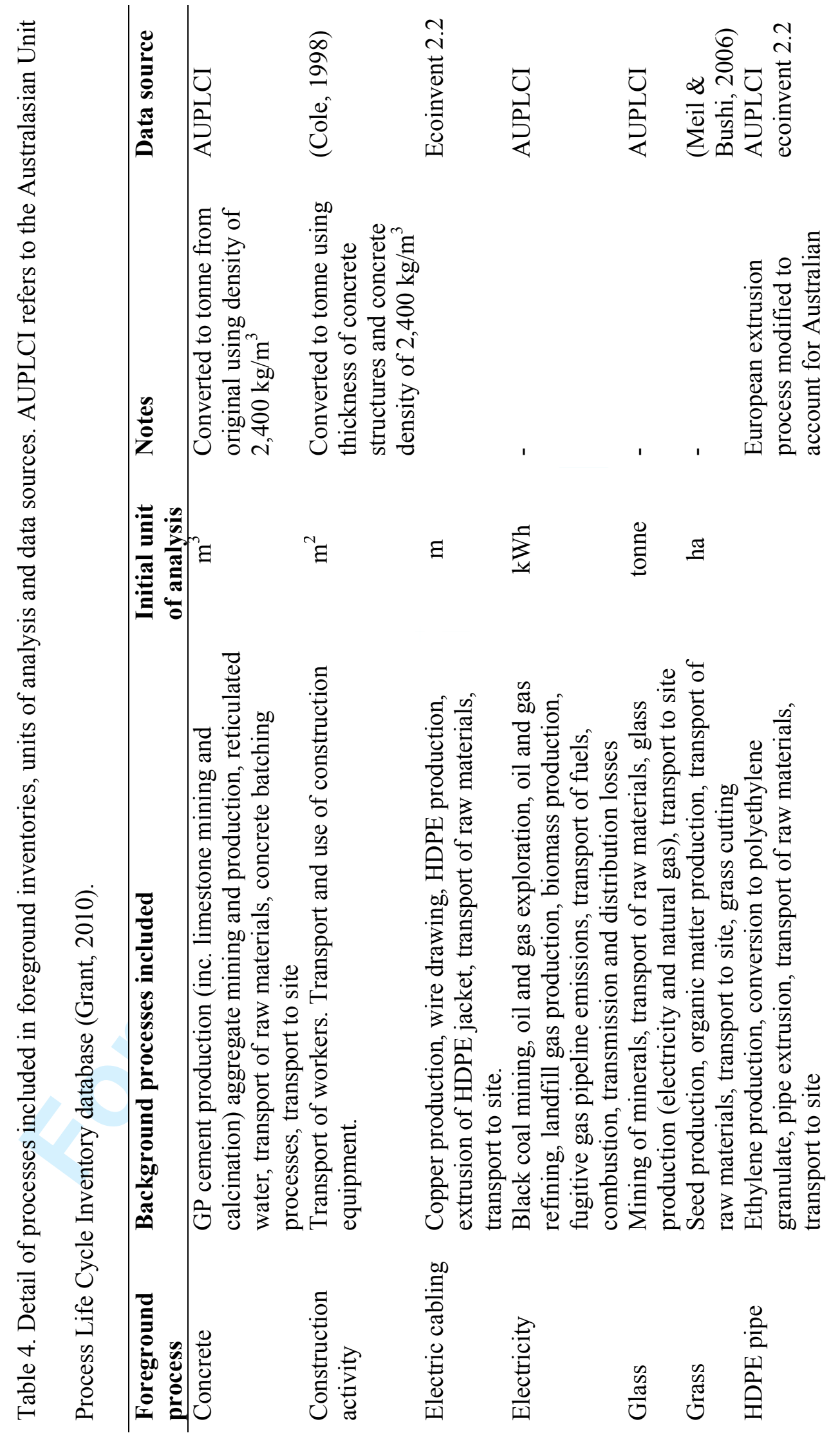




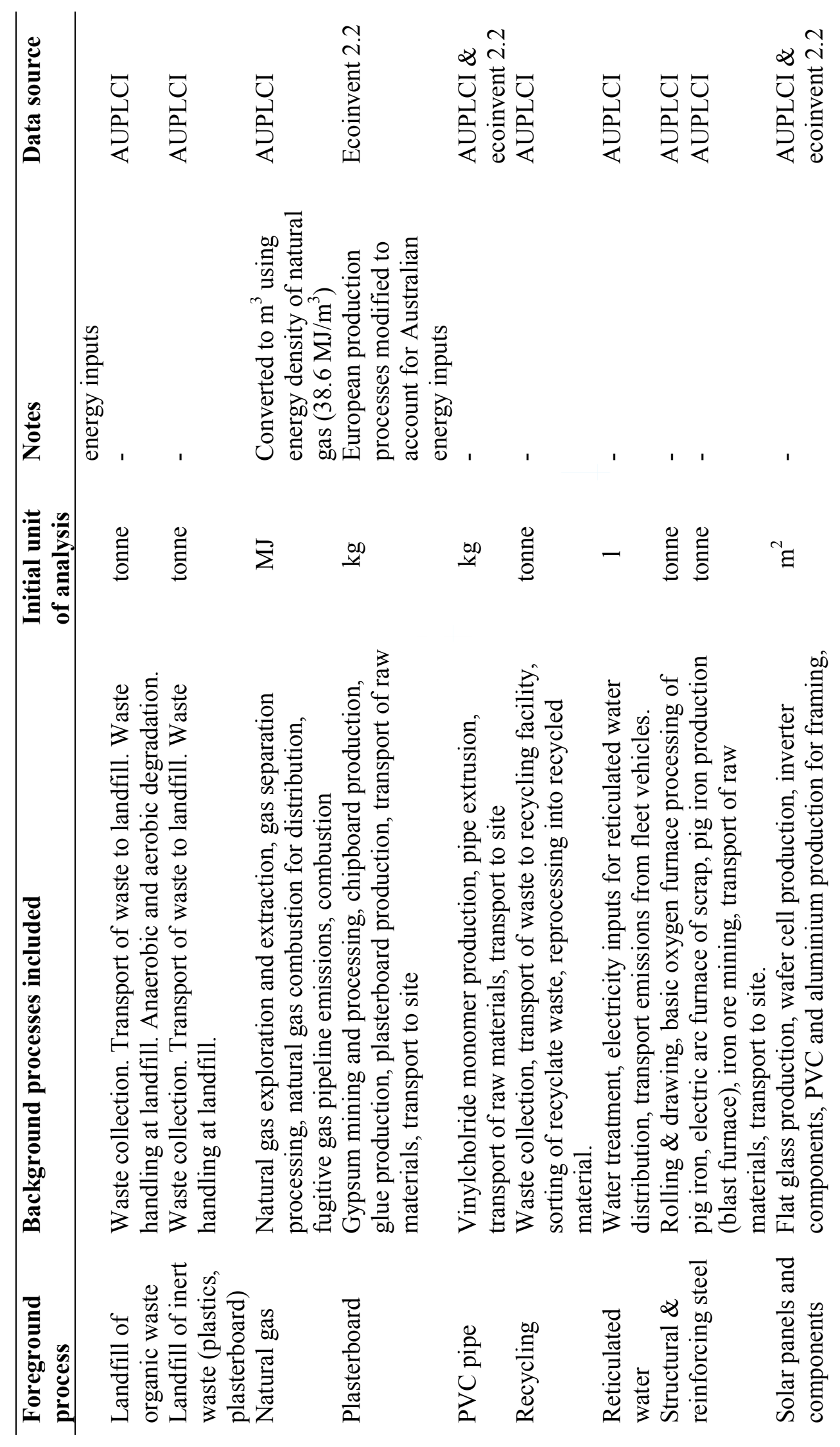




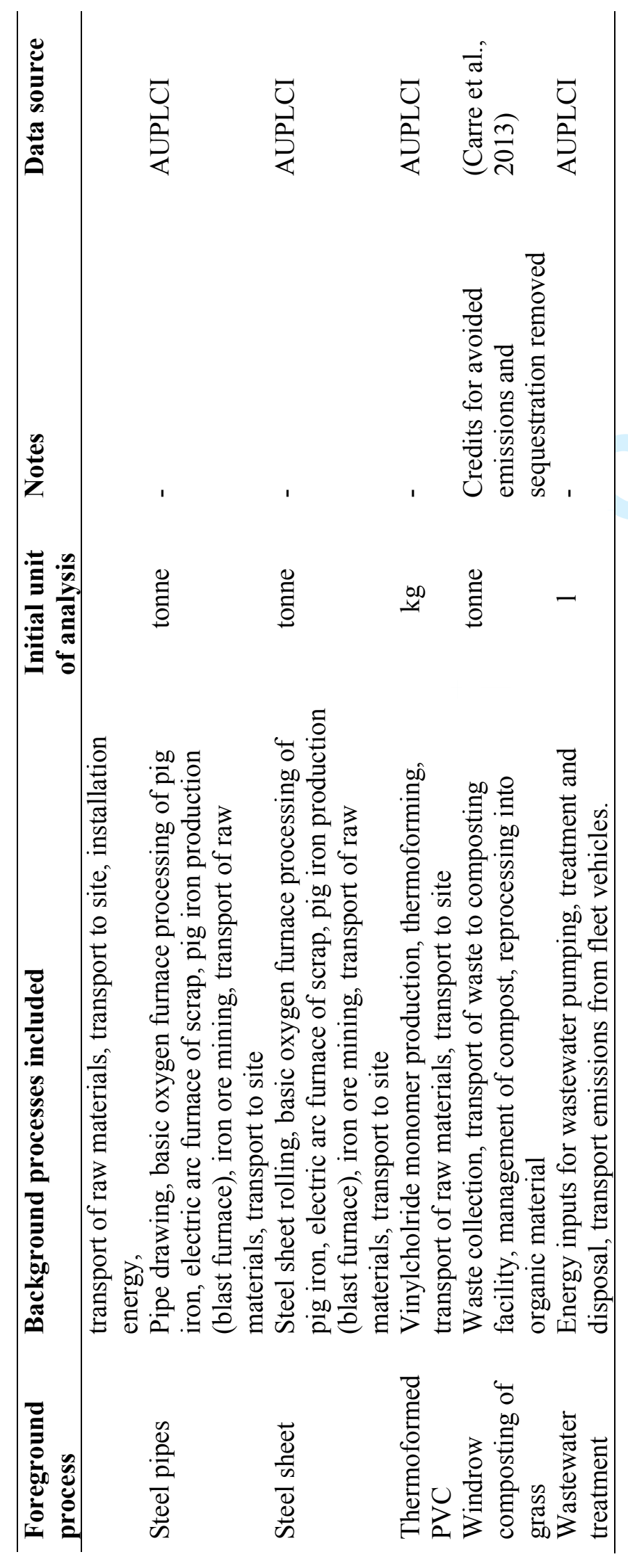


Table 5. Life cycle impact assessment results. Results are reported against the attendance of one person at one AFL event.

\begin{tabular}{lcc}
\hline Life cycle stage & $\begin{array}{c}\text { Greenhouse gas } \\
\text { emissions } \\
(\mathbf{k g ~ C O} \text {-eq) }\end{array}$ & $\begin{array}{c}\text { Contribution to } \\
\text { life cycle stage } \\
(\%)\end{array}$ \\
\hline Construction & 3.65 & 24.7 \\
Base load operations & 10.12 & 68.7 \\
Game day operations & 0.57 & 3.8 \\
Replacement materials & 0.22 & 1.5 \\
$\begin{array}{l}\text { End of life (construction and } \\
\text { replacement materials) }\end{array}$ & 0.19 & 1.3 \\
\hline Total & 14.74 & 100 \\
\hline
\end{tabular}


Table 6. Construction materials impact assessment results. Results are reported against the attendance of one person at one AFL event.

\begin{tabular}{lccc}
\hline Material / process & $\begin{array}{c}\text { Greenhouse gas } \\
\text { emissions } \\
\text { (kg CO2-eq) }\end{array}$ & $\begin{array}{c}\text { Proportion of } \\
\text { construction } \\
\text { impacts } \\
\mathbf{( \% )}\end{array}$ & $\begin{array}{c}\text { Proportion } \\
\text { of } \\
\text { total impacts } \\
\text { (\%) }\end{array}$ \\
\hline Concrete & 1.43 & $39.3 \%$ & $9.7 \%$ \\
Structural steel & 1.31 & $35.9 \%$ & $8.9 \%$ \\
Reinforcing steel & 0.23 & $6.2 \%$ & $1.5 \%$ \\
Construction activity & 0.20 & $5.5 \%$ & $1.4 \%$ \\
Plumbing & 0.13 & $3.5 \%$ & $0.9 \%$ \\
Solar systems & 0.09 & $2.5 \%$ & $0.6 \%$ \\
Steel sheet & 0.08 & $2.3 \%$ & $0.6 \%$ \\
Transport of & 0.08 & $2.2 \%$ & $0.5 \%$ \\
materials & & $1.1 \%$ & $0.3 \%$ \\
Thermoformed PVC & 0.04 & $1.0 \%$ & $0.2 \%$ \\
Plasterboard & 0.04 & $0.3 \%$ & $0.1 \%$ \\
Glass & 0.01 & $<0.1 \%$ & $<0.1 \%$ \\
New grass & $6.61 \mathrm{E}-04$ & $<0.1 \%$ & $<0.1 \%$ \\
Electrical cabling & $7.30 \mathrm{E}-04$ & $100.0 \%$ & $24.7 \%$ \\
\hline Total & 3.65 & & \\
\hline
\end{tabular}


Table 7. Operation impact assessment results. Results are reported against the attendance of one person at one AFL event.

\begin{tabular}{lccc}
\hline Material & $\begin{array}{c}\text { Greenhouse } \\
\text { gas } \\
\text { emissions } \\
\text { (kg CO } \mathbf{2}^{-}\end{array}$ & $\begin{array}{c}\text { Proportion of } \\
\text { operations } \\
\text { impacts } \\
\mathbf{( \% )}\end{array}$ & $\begin{array}{c}\text { Proportion } \\
\text { of } \\
\text { total } \\
\text { impacts } \\
\mathbf{( \% )}\end{array}$ \\
\hline $\begin{array}{l}\text { Baseload - refrigeration, } \\
\text { ventilation and lighting }\end{array}$ & 6.58 & 61.5 & 44.6 \\
Baseload - chillers & 3.29 & 30.8 & 22.3 \\
Baseload - Grass maintenance & 0.25 & 2.3 & 1.7 \\
and disposal & & & $<0.1$ \\
Baseload - water heating & 0.01 & 0.1 & $<0.1$ \\
Baseload - wastewater & 0.003 & 0.02 & 68.6 \\
\hline Total baseload & 10.12 & 94.7 & 1.7 \\
\hline Game day - stadium lighting & 0.25 & 2.3 & 1.6 \\
Game day - waste management & 0.23 & 2.2 & 0.5 \\
Game day - water heating & 0.08 & 0.7 & 0.1 \\
Game day - wastewater & 0.01 & 0.1 & 3.8 \\
treatment & & & 72.5 \\
\hline Total game day & 0.57 & 5.3 & \\
\hline Total & 10.69 & 100.0 & \\
\hline
\end{tabular}


A greenhouse gas assessment of a Stadium in Australia 


\section{A greenhouse gas assessment of a Stadium in Australia}

This paper presents the findings of a greenhouse gas life cycle assessment of a stadium used for sporting events in a sub-tropical region in Australia. Inventories for the construction and operation of a stadium are presented and the greenhouse gas emissions from construction, operations and endof-life waste management are assessed against the attendance of one person at one event. The inclusion of additional economic activities, patron travel, LCA methodology, attendance and stadium life time assumptions, are likely to affect the overall magnitude of the greenhouse gas emissions of one person's' attendance. The assessment shows that the stadium operation accounted for $72.5 \%$ of greenhouse gas emissions, with the operation of base load heating, ventilation and cooling, lighting and refrigeration systems dominating. Addressing the continual operation of these systems represents the best opportunity to reduce greenhouse emissions. Construction impacts account for $24.7 \%$ of impacts, while replacement materials, end of life management of materials are relatively insignificant, contributing to less than $3 \%$ of life cycle greenhouse emissions.

Keywords: life cycle assessment; greenhouse emissions; stadium; sporting events

Subject classification codes: include these here if the journal requires them 


\section{Introduction}

Life cycle assessment (LCA) research has been applied to commercial and residential buildings to better understand environmental impacts and potential environmental mitigation strategies. A number of LCA methods have been utilised for the built environment, including process-based LCA, which accounts for the environmental impacts associated with material and energy flows, and economic input-output (EIO) LCA (Ochoa, Hendrickson, \& Matthews, 2002), which accounts for environmental impacts stemming from economic flows across and within different industry sectors within an economy. Each LCA method has its advantages and disadvantages, some of which are discussed here. Processbased LCA allows for the identification of material and/or energy processes, which drive environmental impacts. A disadvantage of process-based LCA is that it can be time consuming, and as such is limited by the choice of the processes to be included in the assessment (the system boundary). It has been argued that the choice of system boundaries in process-based LCA could exclude between 50\% (Lenzen, 2000) and 87\% (Crawford, 2008) of embodied energy impacts. EOILCA overcomes this limitation by accounting for additional environmental flows associated with a product/service, such as the procurement of professional services (e.g. engineering services). Disadvantages of EIO-LCA include data resolution, which can limit the ability to identify process optimisation and redesign opportunities (Finnveden et al., 2009) and difficulties associated with economic flows beyond the economy being examined (e.g. imports). Hybrid LCA, which combines process-based and EIO LCA has been used to allow for a more 
complete assessment of all environmental flows associated with buildings (Aye, Ngo, Crawford, Gammampila, \& Mendis, 2012; Treloar, Love, Faniran, \& IyerRaniga, 2000).

Irrespective of LCA methodology, the literature on the environmental impacts of sporting stadiums is extremely limited. Collins et al. (2007) reported the ecological footprint (global hectares) and greenhouse gas emissions, using EIO-LCA, of the 2003/04 FA Cup Final at the Millennium Stadium in Cardiff, Wales. The Collins et al. (2007) study accounted for patron transport to the stadium, the provision of food, waste and drink and stadium infrastructure, but excluded stadium operations (e.g. stadium lighting and heating, ventilation and air conditioning systems). This exclusion appears to be a critical oversight as previous process-based LCA studies indicate that the operational impacts of stadiums can contribute to between $31 \%$ and $77 \%$ (Econ Pöyry AB, 2009; Grant, 2001) of total greenhouse gas impacts, depending on the stadium being considered. The greenhouse gas footprint of the 2012 London Olympics were assessed using a hybrid LCA approach (LOC, 2010), but did not include disaggregated results for the stadiums (e.g. Olympic Stadium, Wembley Stadium). The greenhouse gas footprint of the upcoming 2014 FIFA World Cup were assessed using process-based methods (FIFA, 2013):;

In addition to these few studies on stadiums, process-based life cycle assessment has been widely applied to assess the potential environmental impacts in other forms of the built environment, namely commercial and residential buildings (Scheuer, Keoleian, \& Reppe, 2003) (Norman, MacLean, \& Kennedy, 2006) (Norman et al., 2006) (Suzuki \& Oka, 1998) (Blengini, 2009) (Li, 2006) 
(Junnila \& Horvath, 2003) (Junnila, Horvath, \& Guggemos, 2006) (Blanchard \& Reppe, 1998) (Carre, 2010) (Kofoworola \& Gheewala, 2008). The difference in the outcomes of these studies is driven by several factors, including regional scope (e.g. due to climatic variations), building lifetime, building construct and life cycle assessment methodology. Regardless of these variations, the same conclusion can be drawn regarding greenhouse impacts. In all cases, the operation and maintenance phase contributes to the majority $(>50 \%)$ of the building greenhouse impacts. This common conclusion is supported by Satrtori and Hestines (2007), who reviewed 60 energy assessment case studies, including those undertaken using LCA. They demonstrated a linear relationship between operational impacts and life cycle impacts and concluded that the most important aspect of residential and commercial building design is to reduce energy use during the operations phase.

This paper presents a case study of a, process-based greenhouse gas life cycle assessment of an Australian Football League (AFL) stadium in a subtropical region in Australia. The stadium is a multipurpose facility that currently seats a maximum of 25,000 spectators and is capable of being extended to 40,000 seats in the future. The stadium features an Australian Football League (AFL) oval, which is also capable of holding cricket matches, music concerts, cultural festivals, international athletics events and association football (soccer) matches. The electricity for the stadium is supplied from the Queensland grid and is supplemented by a photovoltaic solar panel system, with the panels installed on the stadium's roof. Water for drinking and catering applications isare supplied by athe local municipal reticulated water network. Harvested rain supplies water for 
non-drinking applications, including flushing of toilets and urinals, washing of the stadium, and irrigation of the playing field. The stadium recycles approximately $75 \%$ of glass, paper and cardboard, green waste and comingled plastics generated during sporting events.

This paper adds to the limited body of literature on the environmental impacts of stadiums by firstly providing a disaggregated inventory of the structural materials used in the construction of a stadium. The paper then elucidates on the contribution of the three main life cycle phases by assessing the greenhouse gas emissions related to the main construction materials, as well as those associated with the stadium operation and the end-of life treatment of the construction materials and attendee waste. Finally, this paper identifies specific environmental improvement opportunities by focussing on material and energy process hot-spots.

\section{Method}

The life cycle assessment was undertaken in accordance with the four step procedure for process-LCA outlined in ISO 14040:2006 (ISO, 2006). These four steps include establishing the unit of assessment and system boundary, inventory development, impact assessment and interpretation (results).

\section{Unit of assessment and system boundary}

In LCA, the functional unit is the unit of assessment; all environmental impact results are reported against this unit. The functional unit is intended to reflect the primary function, or service, of a system. Difficulties in defining the primary function of a system can lead to a large variation in reported functional units, 
which can make comparisons between studies problematic. For example, residential and commercial buildings can provide a number of services, including providing shelter, facilitating commercial activities, storage and entertainment. For stadiums, the primary functions are distinctly different to commercial and residential buildings; stadiums can facilitate sports entertainment (e.g. football, baseball or rugby matches), music events or corporate/social events. The primary function of sports stadiums may be defined as the provision of spectator viewing for live sporting events. The hosting of other events (e.g. corporate/social events) is considered to be the stadiums' secondary function.

The functional unit was defined as the provision of entertainment services for attendance of one person at one AFL event in a stadium with a capacity of between 20,000 and 30,000 people.

The system boundary is presented in Figure 1 and includes the main construction and service (e.g. electrical, plumbing) materials, as well as electricity, natural gas, water and waste services associated with stadium operation. The choice of construction materials within the system boundary was based on previous process-based LCAs on stadiums_(Econ Pöyry AB, 2009; Grant, 2001; LOC, 2010).

Travel of attendees can be a significant contributor to greenhouse gas impacts at events. For example, Econ Pöyry suggest that travel can account for approximately $85 \%$ of total greenhouse impacts (INSERT REF). This study focuses on identifying environmental improvement opportunities related to materials used in construction, as well as specific operations of the stadium. As $\underline{\text { such, patron travel, as well as upstream environmental flows associated with }}$ 
economic activity (both lower and higher order) typically assessed using EIO-

$\underline{L C A}$, have been excluded. The process-based life cycle inventory used accounts for environmental flows associated with major higher-order processes, such as energy and materials throughout the supply chain. However, other higher-order environmental flows associated with economic activity may have been excluded.

As the stadium serves multiple functions, a process on how to partition the stadiums' impacts across these functions is required. There is yet no agreed approach on partitioning in LCA. However, ISO 14044:2006 outlines a stepwise procedure to deal with this partitioning. The first step of the ISO 14044:2006 procedure is to increase the level of detail; that is to collate data relating directly to the different functions. Disaggregated data relating to the operation of the stadium serving different functions (e.g. sporting events, corporate events) was not available. The next step in the ISO 14044:2006 procedure is to account for the effects of the secondary functions (co-products) on other systems; a process often termed system expansion. The system expansion approach suggested by Weidema (Weidema, 2001) was adopted and accounts for potential displacement effects of the hosting of corporate events. Using Weidema's approach, two alternate scenarios are possible. In the first scenario, displacement occurs. That is, the hosting of corporate events at the stadium displaces the hosting of a similar event elsewhere. In this scenario, the sporting event function receives credits associated with the avoidance of hosting of corporate events at another facility (e.g. at a hotel). In the second scenario, displacement does not occur. That is, the hosting of corporate events at the stadium does not displace the hosting of a similar event elsewhere. In the second scenario, the sporting events receive no avoidance 
credits and the corporate events are considered free of environmental burden. The applicability of the two scenarios depends whether or not displacement occurs. Whether or not the displacement of corporate events occurs depends on a number of factors, including the availability of facilities to hold corporate events, the ability of other facilities to fulfil user requirements and decision making (Weidema, 2003). An assessment of substitution effects is beyond the scope of this study. However, the two main industries (as classified by the Australian and New Zealand Industry Code system) most likely to be engaged in hosting corporate events are the hotels and resorts industry, and the pubs, bars and nightclub industry. Both of these industries are forecasting revenue growth, indicating increased demand from consumers for products and services provided by these industries (IBISWorld Pty Ltd., 2013a, 2013b). Increased demand means that the hosting of corporate events at facilities other than the stadium may occur regardless of whether or not the stadium hosts corporate events. In this respect, it is considered unlikely that the corporate events held at the stadium will displace corporate events held elsewhere. Following the second scenario outlined above, this means that the sporting function does not receive avoidance credits.

As per ISO 14044:2006, alternative partition methodologies are applicable if system expansion is not possible. The implications of these alternative partitioning methods are discussed later in this paper.

\section{Inventory}

The second stage in process-based LCA is to develop an inventory of emission flows associated with the materials and energy systems used to deliver the functional unit. 
The stadium is typically used for two pre-season trial games and eleven league game days per calendar year; 13 games in total. The projected economic life of the stadium is 30 years, resulting in a total of 390 game-days. This number of game-days is consistent with other regional stadiums in South Africa (Econ Pöyry AB, 2009). The annual crowd attendance for game days in 2011 was 145,333 for eight matches (Austadiums Website, 2013), an average of 18,166 attendees per match. The average attendance in 2012 was lower, with a total of 160,631 people attending over 13 matches (Austadiums Website, 2013), an average of 12,356 attendees per event, with patronage varying between 5,150 people to 16,550 people. - For the purposes of this study, the 2012 attendance figures are used as a basis. In 2012, there were three day games (starting between 2:20 PM and 3:40 PM) and ten night games (starting between 4:40 PM and 7:40 PM). AFL matches typically last for approximately two and a half hours. As such, the games starting at 4:40 PM commence near dusk and are played into the night, with the stadium operating lighting throughout. In addition to the sporting events, the stadium hosted 5,560 attendees at corporate events in 2012. Finally, the stadium employs seven full-time staff.

Table 1 outlines the type, amount, use, emission factors, replacement rates and end-of-life fates for the construction materials considered. The data on the source, amount and type of structural and service materials were provided by the stadium's construction company. The impacts of the construction material were amortised over 390 game days over the thirty year lifetime. This allocation approach is consistent with other greenhouse gas footprints of stadiums (Econ Pöyry AB, 2009). It is considered that the structural materials are unlikely to be 
replaced over the thirty year lifetime. Other materials, including those for services (e.g. toilet cisterns, electrical cabling) and internal fit-outs (e.g. plasterboard) are considered likely to be replaced once over the thirty year period. These lifetime assumptions are consistent with other literature (Scheuer et al., 2003). Because-As the stadium materials will be disposed of in the future, the end-of-life fate is uncertain. Given this uncertainty, materials were assumed to be in landfill or recycled at typical recycling rates (Hardie, Khan, \& Miller, 2006; Nolan-ITU, 2002; Tam, 2009). For materials coming into contact with wastewater (stormwater or sewage) it was assumed that the end-of life was landfill, except for the steel sewer mains, which represent a significant mass and thus are considered likely to be recovered for recycling.

\section{INSERT TABLE 1 HERE}

The impacts of construction activities were estimated using average emission factors for the construction of concrete structural systems, coupled with the total mass of concrete used. An average emission factor of $17.76 \mathrm{~kg} \mathrm{CO} 2$-eq per tonne of concrete was adopted, based on (Cole, 1998). The emission factor accounts for on-site equipment use, worker transportation, and equipment transport (Cole, 1998). Using this approach, construction activity emissions were estimated to be 973.0 tonne $\mathrm{CO}_{2}$-eq.

The stadium operates on a base load each day, with game-day operations adding to this base load. All data relating to the base operation of the stadium was provided by the stadium operator in disaggregated solar and grid electricity inputs, natural gas inputs (for heating of hot water), reticulated water inputs and wastewater outputs. The electricity data were disaggregated into two main 
categories: 1. requirements for chillers, refrigeration and base load lighting, and 2. ventilation. Further disaggregation of the chillers, refrigeration and base load lighting was not possible, due to these services being on the same circuit and being monitored by only one meter. The electricity inputs for base load operations were based on a mix of grid electricity from the Queensland (state) grid (80\%) and solar electricity (20\%). The stadium exports excess electricity generated, but no environmental credits were applied for the potential of exporting excess solar electricity during base load operations. The inventory for baseload operations is provided in Table 2.

\section{INSERT TABLE 2 HERE}

For game-day operations, as indicated in Table 3, there is an increase in the demand for hot water, volume of wastewater discharge, an increase in mass of solid waste generated (due to disposed food, beverage and associated packaging), and for events being held at night, an increase in electricity inputs for the stadium lighting. The water for flushing of toilets and urinals is supplied from rainwater tanks. As the stadium was only recently commissioned, no data were available on the increase in natural gas required for hot water heating, rainwater use for flushing or use of overhead stadium lighting. The natural gas impacts were allocated between the baseload and game-day load based on the amount of time and number of people attending the stadium for different purposes (person.hours). The 160,361 sporting event attendees were assumed to stay for three hours per event, equating to 481,083 person.hours. Similarly, the 5,560 event attendees were assumed to stay for three hours, equating to 16,680 person.hours. The seven fulltime staff were assumed to have worked a total of 1,824 in the calendar year, 
equating to 12,768 person.hours. The sum of these occupancies is 510,531 person.hours. Staff occupancy equates to $2.5 \%$ of the total person.hours. The 2012 gas consumption for the stadium was $18,262.5 \mathrm{~m}^{3}$. It was assumed that the hot-water use profile did not vary with the type of attendee. Baseload operations were attributed with natural gas impacts based on the $2.5 \%$ staff occupancy, equivalent to $456.7 \mathrm{~m}^{3}$ while the remainder of the natural gas consumption was attributed to game-day operations. The impacts of the natural gas used during corporate events were attributed to the sporting events, as per the system expansion procedure described earlier.

\section{INSERT TABLE 3 HERE}

Grass growing, installation, maintenance and disposal impacts were based on previous greenhouse gas studies (Carre, Crossin, \& Clune, 2013; Meil \& Bushi, 2006), with the grass from the playing surface assumed to be replaced every three years.

The disposal of wastewater on game days was estimated based on 1 flush of an 8 litre toilet cistern per attendee. Electricity inputs for stadium lighting (for night games) were calculated based on the number of light towers at the stadium (6), the number of lights per tower (estimated to be 80), the energy rating of typical stadium lights $(2 \mathrm{~kW})$, a $53 \%$ capacity factor for stadium lighting and an average running time of 4 hours per night event (Melbourne Cricket Ground, 2012). Based on these assumptions, the electricity input is $2.04 \mathrm{MWh}$ per night event. The electricity input for night lighting was based on grid electricity. The total solid waste generated by spectators in 2011 was $18,945 \mathrm{~kg}$. This equates to an average of $130.4 \mathrm{~g}$ per attendee per event. The material composition of the 
solid waste was unknown. For modelling purposes, the fraction of plastic and paper (comingled), cardboard and other rubbish were based on an audit of a rugby event in New Zealand (RWC Ltd., 2008). Using the rugby event study, 54\% of waste (by mass) is comingled plastic and paper, $9 \%$ is cardboard, and $37 \%$ is undisclosed waste. The split between plastic and paper was assumed to be $28 \%$ and $72 \%$, based on municipal solid waste mixes in waste streams in Australia (DEWHA, 2010). The recycling rates were unknown, but for cardboard/paper and plastics were estimated to be $60 \%$ and $20 \%$, respectively (DEWHA, 2010). The undisclosed waste and non-recyclable materials generated by attendees were assumed to be disposed of in landfill.

All foreground data were coupled with background datasets from the Australasian Unit Process Life Cycle Inventory (Grant, 2010) and Ecoinvent 2.2 (Ecoinvent, 2007). Details of processes included and data sources are provided in Table 4._The quality of the data varied in terms of temporal and regional relevance, however the data quality was considered appropriate to investigate the directional nature of the greenhouse gas impacts.

INSERT TABLE 5 HERE

\section{Impact assessment}

Life cycle impacts were assessed for the global warming mid-point category. The LCIA was calculated by multiplying the total emissions of the various greenhouse gases by their respective global warming potentials (GWPs), then adding the global warming equivalencies for the various greenhouse gases. GWPs were based on the IPCC 2007 global warming potentials factors for a 100 year timeframe (IPCC, 2007). The greenhouse gases assessed included carbon dioxide, 
methane, nitrous oxide, sulphur hexafluoride and the suite of hydrofluoro-carbons (HFC's) and chlorofluro-carbons (CFC's). Carbon sequestration (e.g. biogenic carbon in landfill) was not included in the impact assessment. All LCIA calculations were performed using SimaPro 7.2.4.

\section{Results}

The total greenhouse gas emissions for one person at one event was $14.74 \mathrm{~kg}$ $\mathrm{CO}_{2}$-eq. The greenhouse gas impact results, and the relative contributions of the construction materials, operation, and the end-of-life phases of the stadium, are reported in Table 5 and Figure 2.

\section{INSERT TABLE 5 HERE}

\section{INSERT FIGURE 2 HERE}

Construction impacts contributed to $3.65 \mathrm{~kg} \mathrm{CO}_{2}$-eq, or $24.7 \%$ of total life cycle greenhouse emissions. The contribution of the materials to the construction impacts are reported in Table 6, with concrete and structural steel dominating, contributing to $1.43 \mathrm{~kg} \mathrm{CO}_{2}$-eq and $1.31 \mathrm{~kg} \mathrm{CO}_{2}$-eq, respectively, equivalent to $9.7 \%$.and $8.9 \%$ of life cycle greenhouse emissions. All other construction activities, including those related to construction activity and service systems, contributed to a total of $6.1 \%$ of life cycle greenhouse emissions.

\section{INSERT TABLE 6 HERE}

The operations account for $72.5 \% \%$ of total life cycle greenhouse impacts. The contributions of the various operational processes to the greenhouse gas emissions profile are reported in Table 7 - -and are dominated by emissions 
associated with baseload operations, accounting for $10.12 \mathrm{~kg} \mathrm{CO}_{2}$-eq, equivalent to $68.6 \%$ of total life cycle greenhouse emissions. In particular, the operation of heating, ventilation and air conditioning (HVAC), lighting and refrigeration systems, which account for $6.58 \mathrm{~kg} \mathrm{CO}_{2}$-eq, or $44.6 \%$ of life cycle greenhouse emissions. Chiller operation during the baseload accounted for $3.29 \mathrm{~kg} \mathrm{CO}_{2}$-eq or $22.3 \%$ of life cycle greenhouse emissions. Game-day operations impacts were relatively minor to baseload operations, contributing to a total of $0.57 \mathrm{~kg} \mathrm{CO}_{2}$-eq. The largest contributor to game-day operations was water heating, with $0.25 \mathrm{~kg}$ $\mathrm{CO} 2$-eq, or $2.3 \%$ of life cycle greenhouse emissions. End of life management of the construction materials and replacement of materials contributed to less than $3 \%$ of total greenhouse emissions, with emissions of $0.22 \mathrm{~kg} \mathrm{CO}_{2}$-eq and $0.19 \mathrm{~kg}$ $\mathrm{CO}_{2}$-eq, respectively.

INSERT TABLE 7 HERE

\section{Discussion}

The $72.5 \%$ contribution of greenhouse gas impacts from the operation of the stadium are driven predominantly by emissions associated with electricity inputs for refrigeration, ventilation and lighting (61.5\% of total greenhouse gas impacts) and chillers (30.8\% of total greenhouse gas impacts). Because- $\underline{A s}$ these systems operate continuously, the electricity inputs for one event are effectively an accumulation of the base-load electricity inputs (when events are not held at the stadium), as well as the additional game-day operational inputs. Electricity inputs for the examined stadium accumulate to 399.2 MWh per game day, equating to an average electricity intensity of $14.66 \mathrm{kWh}$ per person per event (for 2012 attendance figures). 
Electricity intensity values are highly sensitive to attendance rates; as such, when making comparisons with other stadiums, the electricity intensity should be normalised based on a fixed attendance rate. At maximum (100\%) capacity the electricity intensity of the AFL stadium of this study equates to 6.8 $\mathrm{kWh}$ per person per event.

There exists only one study which assesses electricity intensity across a number of different stadiums_(Econ Pöyry AB, 2009). Figure 3 plots electricity intensity versus stadium size for data from this study, assuming $100 \%$ attendance. The Econ Pöyry study utilised a process-based LCA methodology to assess the greenhouse gas emissions associated with the hosting of the 2010 FIFA World Cup. The Econ Pöyry -study includes projections of electricity use for each stadium utilised during the event. In Figure 3, most stadiums have an electricity intensity of between $4.0 \mathrm{kWh}$ and $4.5 \mathrm{kWh}$ per person per event, approximately $65 \%$ of the intensity for that of the AFL stadium.

\section{INSERT FIGURE 3 HERE}

Stadiums are unique in that they experience large surges in occupancy over a short period of time. These large variations in occupancy can be problematic for refrigeration and HVAC systems and electrical systems more broadly. Indeed, the operator of the stadium under study indicated that the continuous operation of the stadiums refrigeration, HVAC and chilling systems was necessary to avoid overloading electrical circuits during peak demand (e.g. during an event). The continual operation of the refrigeration, HVAC and chilling systems in this study could partly explain the high electricity intensity, relative to

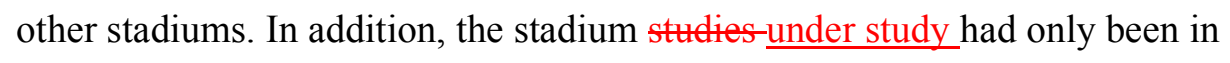


operation for one year and the operation may not have been optimised. Finally, thermal loads placed on the HVAC systems in the case-study stadium may have been higher than for those studies by Econ Pöyry, e.g. due to climatic variations.

In the review of the electricity intensity of the South African stadiums, the Moses Mabhida stadium is particularly important, with an intensity of $2.77 \mathrm{kWh}$ per person per event, a 37\% reduction relative to the average of the other South African stadiums. This reduction is driven by a number of design interventions, including the utilisation of natural ventilation and lighting, and heat pumps for water heating. Importantly, the Moses Mabhida stadium utilises systems which can be selectively switched off locally, thereby reducing base-load energy requirements by $20 \%$ (UEMP, 2010). This feature is in contrast to the stadium in this study, where the base-load systems operate continuously. Addressing the continual operation of systems in the case-study stadium represents a significant opportunity to reduce the greenhouse gas emissions associated with operation of the stadium.

Compared with the operations phase, the environmental impacts associated with the stadium construction are relatively minor (24.7\%). These construction greenhouse gas impacts are dominated by structural steel (8.9\%) and concrete $(9.7 \%)$. The emissions associated with concrete eould may be reduced by replacing general purpose cement within the concrete with supplementary cementetious materials, such as ground-granulated blast furnace slag, which have been shown to offer greenhouse gas reductions of between $22 \%$ and $40 \%$ (Flower \& Sanjayan, 2007; Heidrich, Hinczak, \& Ryan, 2005). 


\section{Limitations}

One aim of this study was to investigate the material and energy processes which drive the greenhouse gas emissions associated with the construction, operation and end-of-life of a stadium. This assessment included a quantification of the total greenhouse gas emissions associated with attendance at a sporting event. This quantification has a number of important limitations, which are likely to affect the overall magnitude of the greenhouse gas impacts of attending a sporting match.

\section{Exclusion of travel}

The transportation of the spectators to the venue was not included in this life cycle assessment. It is recognised that spectator transport can be a significant contributor to greenhouse gas emissions. Econ Pöyry estimate that spectator transport can contribute to more than $85 \%$ of total greenhouse gas impacts (2009), but this was for an international sporting event, rather than a domestic sporting event. Similarly, attendee travel was estimated to account for $87 \%$ of Live Earth concerts (Live Earth, 2007), held at seven different stadiums. Interestingly, only $2 \%$ of the attendees travelled by air, yet they contributed to $80 \%$ of greenhouse gas emissions (Live Earth, 2007). In this respect, estimations of greenhouse gas emissions associated with attendee travel are highly sensitive to the number travelling by air. No literature was available on attendee travel behaviour for AFL matches in Australia, or indeed for any sporting code in Australia. Given that there are likely to be at least some spectators using air travel, it is highly likely that attendee travel would contribute to a significant proportion of greenhouse gas emissions. Data surveys on domestic spectator travel behaviour are warranted and 
would need to be undertaken to investigate and quantify the significance of this on environmental impacts.

\section{Partition methodology}

The default assumption in this study was that stadium construction, operation and demolition impacts were wholly attributable to attendees at sporting events, and those attending corporate events received no environmental burden. It could be argued that some of these impacts should be attributable to those attending corporate events at the stadium. A number of alternative partitioning approaches could-may be used to allocate the life cycle impacts across all patrons, including methods based on attendance values, or methods accounting for revenue (economic allocation). Given that $96.6 \%$ of attendance was for sporting events, and $3.4 \%$ was for corporate events, partitioning using one of the alternate approaches would reduce the magnitude of the sport-event based greenhouse gas values, but would not alter the dominant processes contributing to the environmental impacts.

\section{Stadium lifetime and attendance}

The default assumption in this study was that the greenhouse emissions associated with construction and end of life material waste management were amortised equally over a total attendance of approximately 4.81 million people over the 390 events over thirty years. Should the total number of attendees increase over this period, then the greenhouse gas emissions associated with construction and end of life will decrease. For example, if the average attendance increased to 20,000 per event (approximately 80\% capacity), the contribution from construction impacts 
would be diluted from $3.65 \mathrm{~kg} \mathrm{CO}_{2}$-eq to $2.25 \mathrm{~kg} \mathrm{CO}_{2}$-eq. Likewise, should the life expectancy be extended beyond thirty years, then the greenhouse gas emissions associated with construction and end of life will decrease. The changes in construction and end of life impacts may not be linear, due to different material replacement requirements.

The greenhouse gas emissions profile presented is based on an average patronage for one year and total energy and material flows for one years' operation. Given that the patronage during that year varied from 5,150 people to 16,550 people, it might be expected that the greenhouse gas emissions profile would change with attendance. The aggregated nature of the operational data provided meant that energy and material requirements for different attendances, including marginal increases in energy/material requirements per spectator, could not be acquired nor determined. Nevertheless, it would be expected that the greenhouse gas emissions from operations attributed to an individual's attendance would vary, depending on the total attendance.

\section{Exclusion of upstream processes associated with construction activity}

This study utilised process-based LCA and did not incorporate any economic input-output LCA (EIO-LCA) modelling. The use of economic input-output LCA, coupled with process-based LCA can provide a broader system boundary to provide a more comprehensive assessment by including economic activity not readily captured by process-based LCA, such as the impacts associated with engineering services. The stadium was completed in 2010, costing AU\$144.2 million. A preliminary EIO-LCA assessment was performed using the Australian 2008-09 EIO database_(Grant, 2013)(Meil \& Bushi, 2006), assuming that the 
economic activity was attributable to the non-residential building construction economic sector. An annual inflation rate of 2.7\% between 2008-09 and 2009-10 (ABS, 2012)_-was used to adjust the construction cost to 2008-09 values (AU\$140.4 million). The same impact assessment method as for the processbased LCA was used. Using this approach, the stadium construction impacts were 56,783.32 tonne $\mathrm{CO}_{2}$-eq; approximately three times the impacts of the $16,503.3$ tonne $\mathrm{CO}_{2}$-eq derived using the process-LCA approach. The scale of the difference between the two methods is consistent with other comparisons between process- and EIO-based LCAs (Crawford, 2008). This preliminary EIO-LCA assessment suggests that the inclusion of other economic activities would increase the impacts of the stadium construction.

\section{Conclusion}

This paper presents an inventory and assessment of the life cycle greenhouse gas impacts of an Australian Football League stadium, using a process-based LCA approach. The greenhouse gas impacts were determined to be $14.74 \mathrm{~kg} \mathrm{CO}_{2}$-eq per person per event based on the system boundary and analysis presented -9 These impacts are likely to be higher should the system boundary be expanded to include attendee travel and other upstream economic activities, or if assumptions regarding attendance and stadium life expectancy vary. The operation of the stadium contributed to the majority of life cycle greenhouse gas emissions, accounting for $72.5 \%$ of total emissions. The operational impacts were mostly driven by emissions associated with continually-operating electrical baseload refrigeration, HVAC and lighting equipment. The continual operation of these systems was necessary so as to not overload electrical circuits during changes in 
peak/off-peak demand. Allowing for intermittent operation of these systems could may represents the greatest opportunity to reduce the greenhouse gas impacts over the life cycle of the stadium.. These conclusions reinforce the importance and relevance of future research into the design of stadium for efficient operation and thereby reduction of environmental impacts.

\section{Acknowledgement}

[--- removed for double-blind process --- ]

\section{References}

ABS. (2012). Consumer Price Index. Australia. December Quarter 2011. Canberra: Australian Bureau of Statistics.

Austadiums Website. (2013). Crowds. Retrieved 18/01/2013 http://www.austadiums.com/sport/crowds.php

Aye, L., Ngo, T., Crawford, R. H., Gammampila, R., \& Mendis, P. (2012). Life cycle greenhouse gas emissions and energy analysis of prefabricated reusable building modules. Energy and Buildings, 47, 159-168.

Blanchard, S., \& Reppe, P. (1998). Life Cycle Analysis of a Residential Home in Michigan. University of Michigan, Ann Arbor.

Blengini, G. A. (2009). Life cycle of buildings, demolition and recycling potential: A case study in Turin, Italy. Building and Environment, 44(2), 319-330.

Carre, A. (2010). A Comparative Life Cycle Assessment of Alternative Constructions of a Typical Australian House Design Melbourne: Forest \& Wood Products Australia Limited.

Carre, A., Crossin, E., \& Clune, S. (2013). LCA of Kerbside Recycling in Victoria. Report for Sustainability Victoria. Melbourne: RMIT University.

Cole, R. J. (1998). Energy and greenhouse gas emissions associated with the construction of alternative structural systems. Building and Environment, 34(3), 335-348.

Collins, A., Flynn, A., Munday, M., \& Roberts, A. (2007). Assessing the environmental consequences of major sporting events: the 2003-04 FA Cup Final. Urban Studies, 44(3), 457-476.

Crawford, R. H. (2008). Validation of a hybrid life-cycle inventory analysis method. Journal of Environmental Management, 88(3), 496-506.

DEWHA. (2010). National Waste Report 2010. Australian Government. Department of the Environment, Water, Heritage and the Arts.

Ecoinvent. (2007). Ecoinvent data v2.2. Switzerland: Swiss Centre for Life Cycle Inventories. 
Econ Pöyry AB. (2009). Feasibility Study For A Carbon Neutral 2010 FIFA World Cup In South Africa. Stockholm: Econ Pöyry AB.

FIFA. (2013). FIFA World Cup Brasil. Sustainability. Summary of the 2014 FIFA World Cup Brazil Carbon Footprint: Fédération Internationale de Football Association, 2014 FIFA World Cup Organising Committee Brazil, MGM Innova do Brasil Ltda.

Finnveden, G., Hauschild, M. Z., Ekvall, T., Guinée, J., Heijungs, R., Hellweg, S., ... Suh, S. (2009). Recent developments in Life Cycle Assessment. Journal of Environmental Management, 91(1), 1-21.

Flower, D., \& Sanjayan, J. (2007). Green house gas emissions due to concrete manufacture. The International Journal of Life Cycle Assessment, 12(5), 282-288.

Grant, T. (2001). The Olympic stadium analysed using the DPWS tool. Retrieved 02 October 2012, from http://intro2sportsarchitecture.files.wordpress.com/2011/05/stadiumaustral ialca1.pdf

Grant, T. (2010). Australasian Unit Process Life Cycle Inventory. Published by Life Cycle Strategies Pty Ltd, Melbourne.

Grant, T. (2013). Australia Input Output 2008-09 greenhouse gas database. Published by Life Cycle Strategies Pty Ltd, Melbourne.

Hardie, M., Khan, S., \& Miller, G. (2006). Waste minimisation in office refurbishment projects : an Australian perspective. eprints.qut.edu.au/27532/1/27532.pdf

Heidrich, C., Hinczak, I., \& Ryan, B. (2005). SCM's potential to lower Australia's greenhouse gas emissions profile. Paper presented at the Australasian Slag Association Conference, Sydney.

IBISWorld Pty Ltd. (2013a). IBISWorld Industry Report H4401. Hotels and Resorts in Australia.

IBISWorld Pty Ltd. (2013b). IBISWorld Industry Report H4510. Pubs, Bars and Nightclubs in Australia.

IPCC. (2007). Climate Change 2007: The Physical Science Basis. Cambridge: Cambridge University Press.

ISO. (2006). ISO 14040:2006(E) Environmental management - Life cycle assessment - Principles and framework. Geneva: International Organization for Standardization.

Junnila, S., \& Horvath, A. (2003). Life-Cycle Environmental Effects of an Office Building. Journal of Infrastructure Systems, 9(4), 157-166.

Junnila, S., Horvath, A., \& Guggemos, A. (2006). Life-Cycle Assessment of Office Buildings in Europe and the United States. Journal of Infrastructure Systems, 12(1), 10-17.

Kofoworola, O., \& Gheewala, S. (2008). Environmental life cycle assessment of a commercial office building in Thailand. The International Journal of Life Cycle Assessment, 13(6), 498-511.

Lenzen, M. (2000). Errors in Conventional and Input-Output—based Life-Cycle Inventories. Journal of Industrial Ecology, 4(4), 127-148.

Li, Z. (2006). A new life cycle impact assessment approach for buildings. Building and Environment, 41(10), 1414-1422. 
Live Earth. (2007). Live Earth Carbon Assessment \& Footprint Report. Beverly Hills: Live Earth, LLC.

LOC. (2010). London 2012. Carbon footprint study - Methodology and reference footprint: London Organising Committee of the Olympic Games and Paralympic Games Ltd, .

Meil, J., \& Bushi, L. (2006). Estimating the Required Global Warming Offsets to Achieve a Carbon Neutral Synthetic Field Turf System Installation: Athena Institute.

Melbourne Cricket Ground. (2012). MCG Light Towers. Retrieved 04 October 2012, from http://www.mcg.org.au/The\%20MCG\%20Stadium/Facts\%20and\%20Figu res/Light $\% 20$ Towers.aspx? $\mathrm{p}=1 \& \mathrm{Q}=$

Nolan-ITU. (2002). Recycling - How Does Australia Compare? : Nolan-ITU Pty Ltd.

Norman, J., MacLean, H., \& Kennedy, C. (2006). Comparing High and Low Residential Density: Life-Cycle Analysis of Energy Use and Greenhouse Gas Emissions. Journal of Urban Planning and Development, 132(1), 1021.

Ochoa, L., Hendrickson, C., \& Matthews, H. (2002). Economic Input-output Lifecycle Assessment of U.S. Residential Buildings. Journal of Infrastructure Systems, 8(4), 132-138.

RWC Ltd. (2008). Case Study - Reducing the environmental impact of sporting events in stadia: Rugby World Cup Limited.

Sartori, I., \& Hestnes, A. G. (2007). Energy use in the life cycle of conventional and low-energy buildings: A review article. Energy and Buildings, 39(3), 249-257.

Scheuer, C., Keoleian, G. A., \& Reppe, P. (2003). Life cycle energy and environmental performance of a new university building: modeling challenges and design implications. Energy and Buildings, 35(10), 10491064.

Suzuki, M., \& Oka, T. (1998). Estimation of life cycle energy consumption and $\mathrm{CO} 2$ emission of office buildings in Japan. Energy and Buildings, 28(1), $33-41$.

Tam, V. W. Y. (2009). Comparing the implementation of concrete recycling in the Australian and Japanese construction industries. Journal of Cleaner Production, 17(7), 688-702.

Treloar, G. J., Love, P. E. D., Faniran, O. O., \& Iyer-Raniga, U. (2000). A hybrid life cycle assessment method for construction. Construction Management and Economics, 18(1), 5-9.

UEMP. (2010). 2010 FIFA World Cup. Moses Mabhida Stadium. Environmental performance enhanced: Urban Environmental Management Programme.

Weidema, B. P. (2001). Avoiding Co-Product Allocation in Life-Cycle Assessment. Journal of Industrial Ecology, 4(3), 11-33.

Weidema, B. P. (2003). Market information in life cycle assessment. 


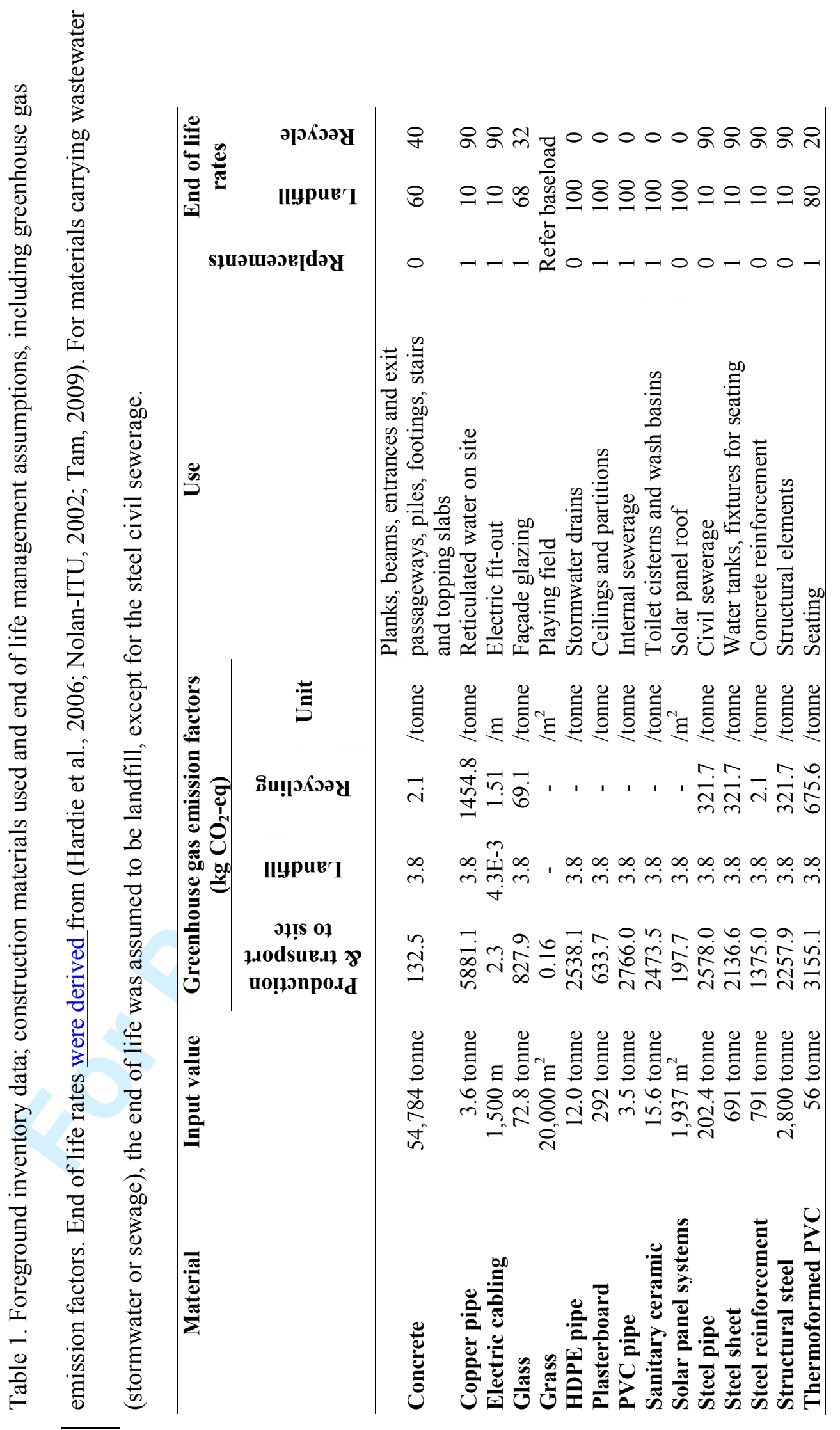




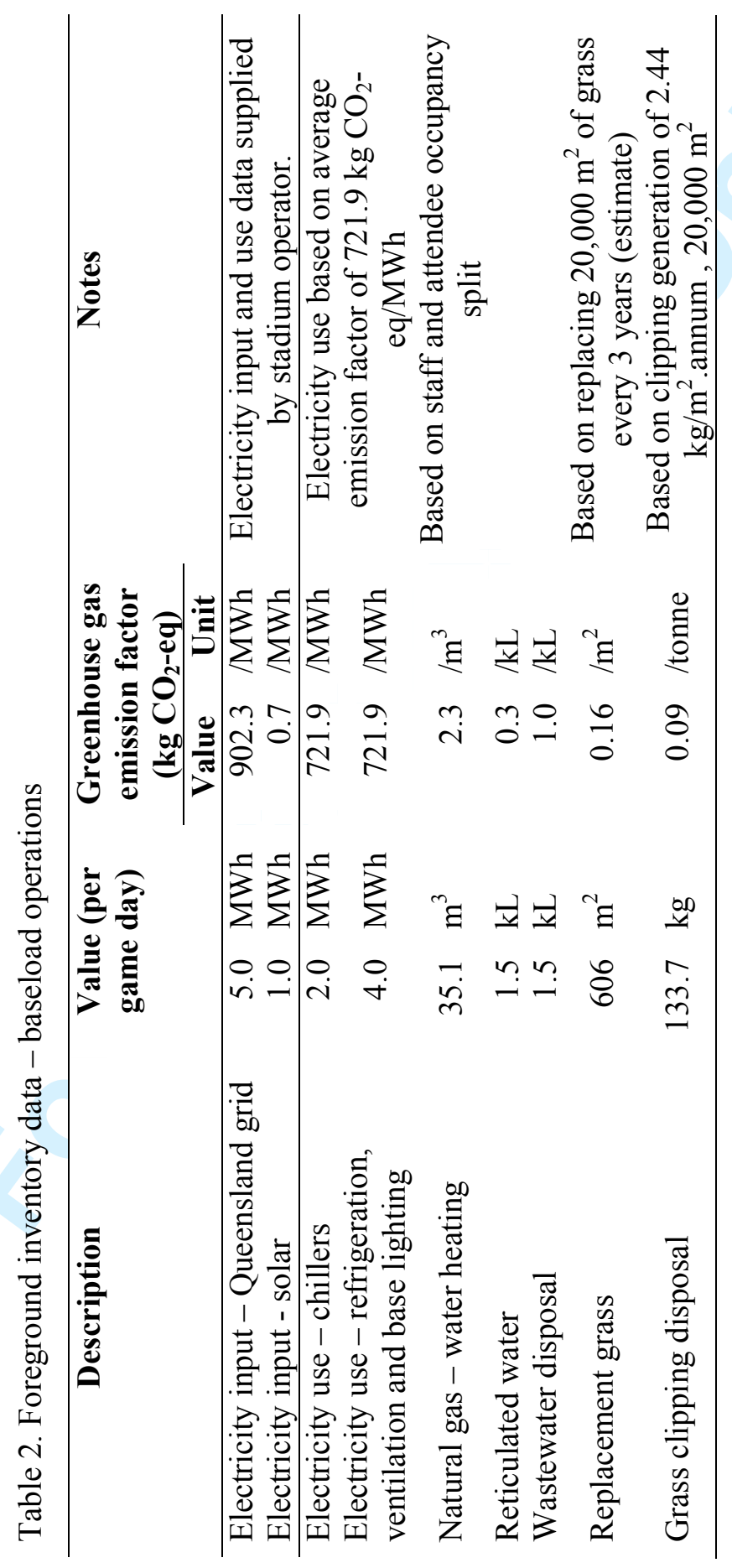




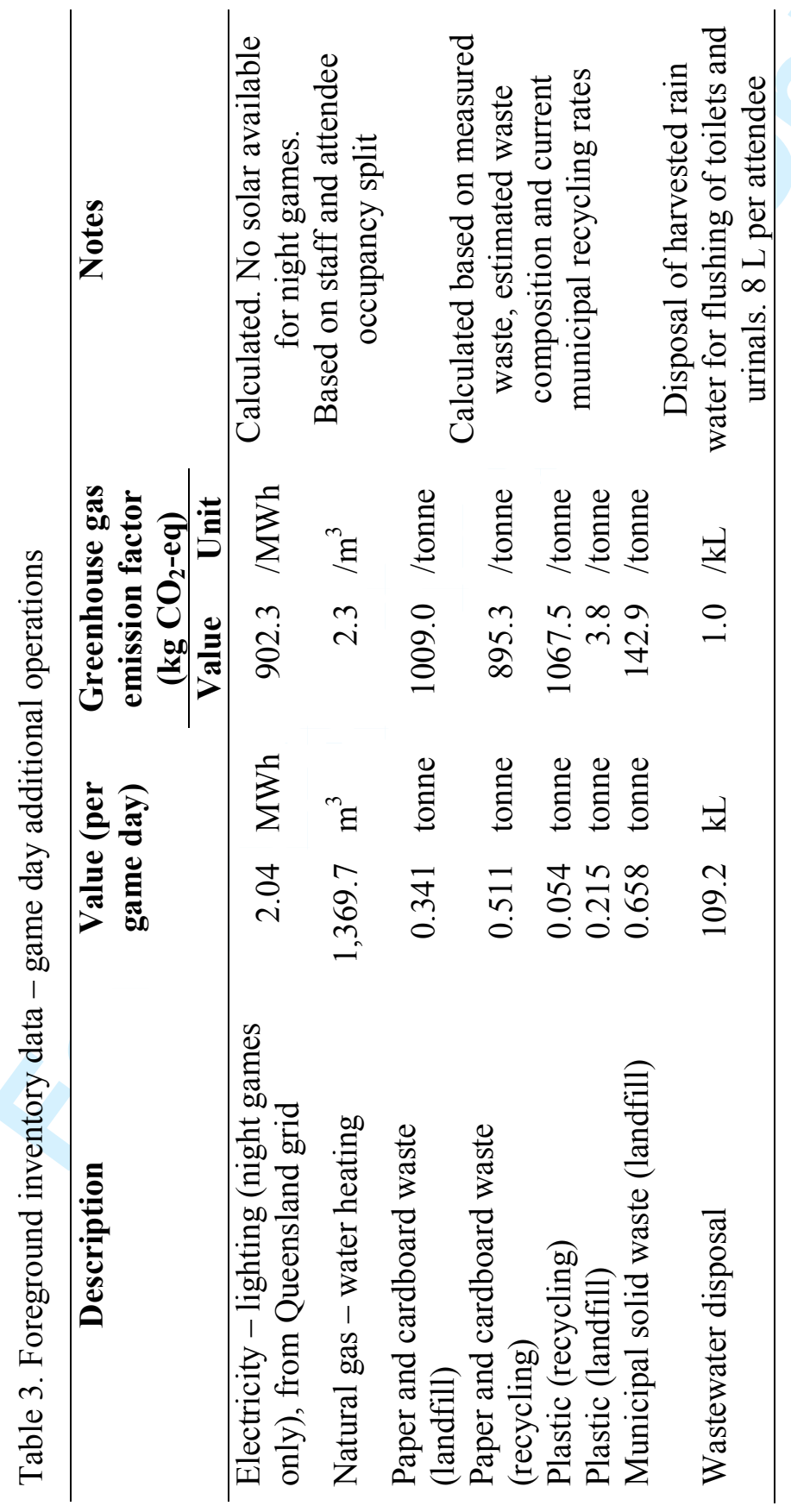




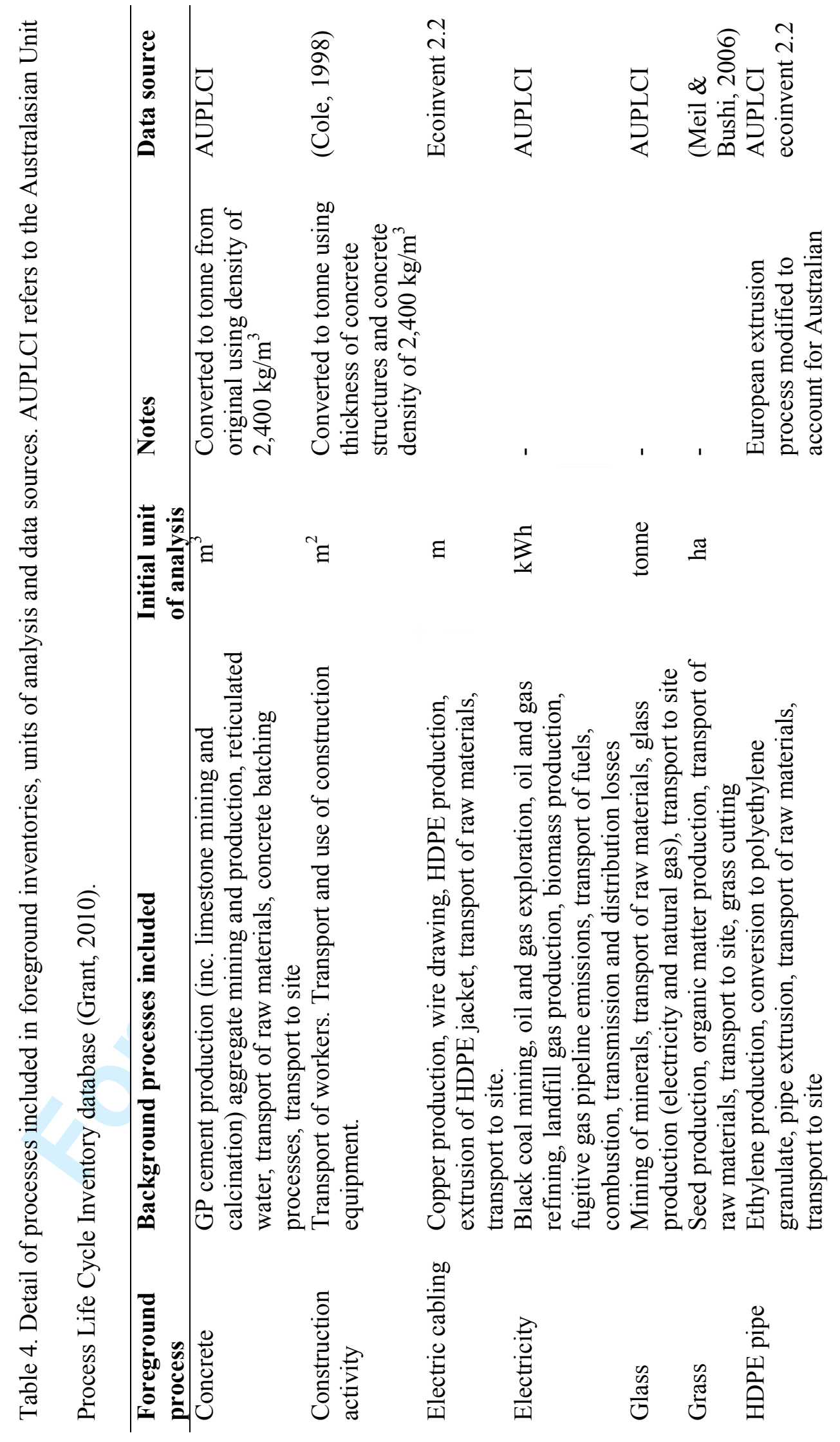




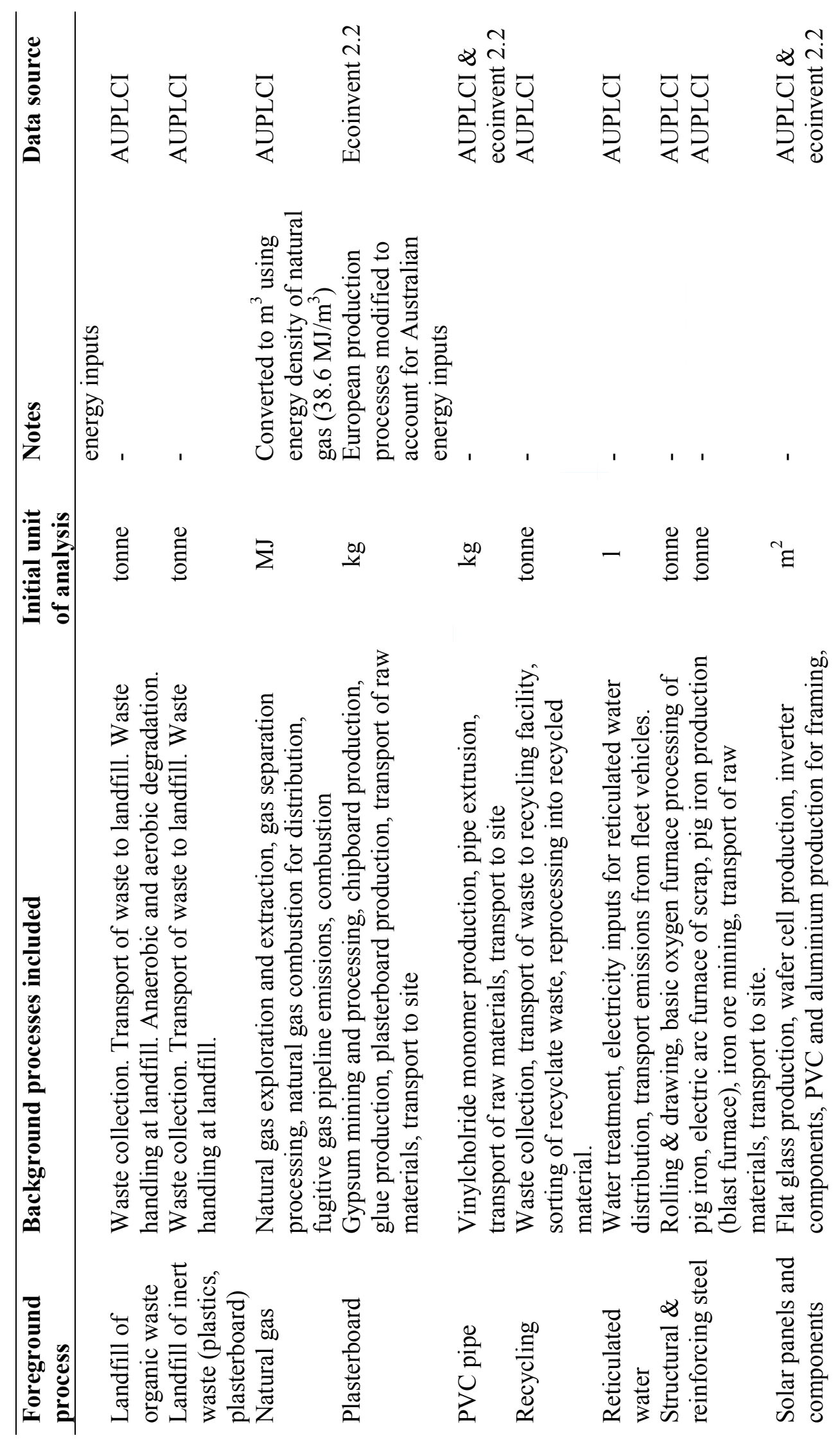




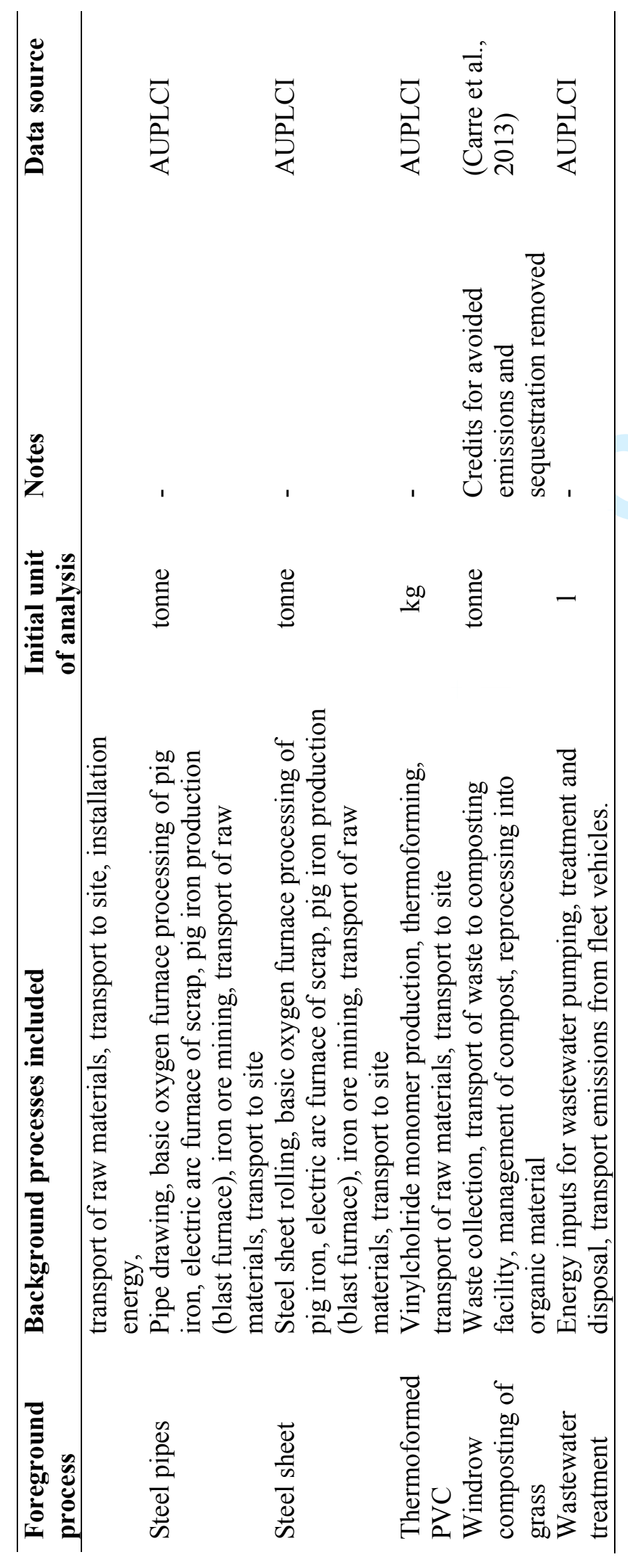


Table 5. Life cycle impact assessment results. Results are reported against the attendance of one person at one AFL event.

\begin{tabular}{lcc}
\hline Life cycle stage & $\begin{array}{c}\text { Greenhouse gas } \\
\text { emissions } \\
(\mathbf{k g ~ C O} \text {-eq) }\end{array}$ & $\begin{array}{c}\text { Contribution to } \\
\text { life cycle stage } \\
(\%)\end{array}$ \\
\hline Construction & 3.65 & 24.7 \\
Base load operations & 10.12 & 68.7 \\
Game day operations & 0.57 & 3.8 \\
Replacement materials & 0.22 & 1.5 \\
$\begin{array}{l}\text { End of life (construction and } \\
\text { replacement materials) }\end{array}$ & 0.19 & 1.3 \\
\hline Total & 14.74 & 100 \\
\hline
\end{tabular}


Table 6. Construction materials impact assessment results. Results are reported against the attendance of one person at one AFL event.

\begin{tabular}{lccc}
\hline Material / process & $\begin{array}{c}\text { Greenhouse gas } \\
\text { emissions } \\
\text { (kg CO} \text {-eq) }\end{array}$ & $\begin{array}{c}\text { Proportion of } \\
\text { construction } \\
\text { impacts } \\
\mathbf{( \% )}\end{array}$ & $\begin{array}{c}\text { Proportion } \\
\text { of } \\
\text { total impacts } \\
\mathbf{( \% )}\end{array}$ \\
\hline Concrete & 1.43 & $39.3 \%$ & $9.7 \%$ \\
Structural steel & 1.31 & $35.9 \%$ & $8.9 \%$ \\
Reinforcing steel & 0.23 & $6.2 \%$ & $1.5 \%$ \\
Construction activity & 0.20 & $5.5 \%$ & $1.4 \%$ \\
Plumbing & 0.13 & $3.5 \%$ & $0.9 \%$ \\
Solar systems & 0.09 & $2.5 \%$ & $0.6 \%$ \\
Steel sheet & 0.08 & $2.3 \%$ & $0.6 \%$ \\
Transport of & 0.08 & $2.2 \%$ & $0.5 \%$ \\
materials & 0.04 & $1.1 \%$ & $0.3 \%$ \\
Thermoformed PVC & 0.04 & $1.0 \%$ & $0.2 \%$ \\
Plasterboard & 0.01 & $0.3 \%$ & $0.1 \%$ \\
Glass & $6.61 \mathrm{E}-04$ & $<0.1 \%$ & $<0.1 \%$ \\
New grass & $7.30 \mathrm{E}-04$ & $<0.1 \%$ & $<0.1 \%$ \\
Electrical cabling & 3.65 & $100.0 \%$ & $24.7 \%$ \\
\hline Total & & & \\
\hline
\end{tabular}


Table 7. Operation impact assessment results. Results are reported against the attendance of one person at one AFL event.

\begin{tabular}{lccc}
\hline Material & $\begin{array}{c}\text { Greenhouse } \\
\text { gas } \\
\text { emissions } \\
\text { (kg CO } \mathbf{2}^{-}\end{array}$ & $\begin{array}{c}\text { Proportion of } \\
\text { operations } \\
\text { impacts } \\
\mathbf{( \% )}\end{array}$ & $\begin{array}{c}\text { Proportion } \\
\text { of } \\
\text { total } \\
\text { impacts } \\
\mathbf{( \% )}\end{array}$ \\
\hline $\begin{array}{l}\text { Baseload - refrigeration, } \\
\text { ventilation and lighting }\end{array}$ & 6.58 & 61.5 & 44.6 \\
Baseload - chillers & 3.29 & 30.8 & 22.3 \\
Baseload - Grass maintenance & 0.25 & 2.3 & 1.7 \\
and disposal & & & $<0.1$ \\
Baseload - water heating & 0.01 & 0.1 & $<0.1$ \\
Baseload - wastewater & 0.003 & 0.02 & 68.6 \\
\hline Total baseload & 10.12 & 94.7 & 1.7 \\
\hline Game day - stadium lighting & 0.25 & 2.3 & 1.6 \\
Game day - waste management & 0.23 & 2.2 & 0.5 \\
Game day - water heating & 0.08 & 0.7 & 0.1 \\
Game day - wastewater & 0.01 & 0.1 & 3.8 \\
treatment & & & 72.5 \\
\hline Total game day & 0.57 & 5.3 & \\
\hline Total & 10.69 & 100.0 & \\
\hline
\end{tabular}


Figure 1. System boundary for streamlined assessment on stadium. Shared processes are shaded in grey

Figure 2. Life cycle greenhouse gas impacts. Results are reported per person, per event.

Figure 3. Electricity intensity for 2010 FIFA World Cup stadiums in South Africa. The Moses Mabhida stadium (circled) has lower electricity intensity than the other stadium, instigated through a number of energy reduction intervention strategies. 
